NBER WORKING PAPER SERIES

\title{
MEASURING THE COST OF REGULATION: \\ A TEXT-BASED APPROACH
}

\author{
Charles W. Calomiris \\ Harry Mamaysky \\ Ruoke Yang \\ Working Paper 26856 \\ http://www.nber.org/papers/w26856
}

\author{
NATIONAL BUREAU OF ECONOMIC RESEARCH \\ 1050 Massachusetts Avenue \\ Cambridge, MA 02138 \\ March 2020
}

We are grateful to the Data Science Institute at Columbia University for financial support, and S\&P Global Market Intelligence for providing us with the data for this study. We thank Glenn Blomquist (discussant), and seminar participants at the American Enterprise Institute, Imperial College, Colorado State, Utah State, University of Texas, and the 2020 Southern Economic Association Conference for their comments. We thank Roya Arab Loodaricheh and Hongyu Wu for excellent research assistance. The views expressed here are the authors' and do not necessarily reflect the views of the Securities and Exchange Commission. This paper was initially released prior to Ruoke Yang joining the Commission. The Securities and Exchange Commission disclaims responsibility for any private publication or statement of any SEC employee or Commissioner. This article expresses the authors' views and does not necessarily reflect those of the Commission, the Commissioners, members of the staff, or the National Bureau of Economic Research.

NBER working papers are circulated for discussion and comment purposes. They have not been peerreviewed or been subject to the review by the NBER Board of Directors that accompanies official NBER publications.

(C) 2020 by Charles W. Calomiris, Harry Mamaysky, and Ruoke Yang. All rights reserved. Short sections of text, not to exceed two paragraphs, may be quoted without explicit permission provided that full credit, including $\odot$ notice, is given to the source. 
Measuring the Cost of Regulation: A Text-Based Approach

Charles W. Calomiris, Harry Mamaysky, and Ruoke Yang

NBER Working Paper No. 26856

March 2020, Revised July 2022

JEL No. G18,G38,K2,L51

\section{ABSTRACT}

We derive a measure of firm-level regulatory exposure from the text of corporate earnings calls. We use this measure to study the effect of regulation on companies' growth, leverage, profitability, and equity returns. Higher regulatory exposure results in slower sales and asset growth, lower leverage, reduced profitability, but higher post-call equity returns. These effects are mitigated for larger firms. Our findings suggest that both compliance risk and physical operational cost are consequences of increased regulation, but the magnitude of the effects of compliance risk are larger. The topical context of regulation is important for future firm-level outcomes.

Charles W. Calomiris

Columbia Business School

Kravis 1101

665 W 130th St.

New York, NY 10027

and NBER

cc374@columbia.edu

Harry Mamaysky

Columbia Business School

Kravis 1153

665 W 130th St.

New York, NY 10027

hm2646@columbia.edu
Ruoke Yang Imperial College Business School 5.09A, 53 Prince's Gate South Kensington Campus United Kingdom ruoke.yang@imperial.ac.uk

Data page is available at http://www.measuringregulation.com

An internet appendix is available at http://www.nber.org/data-appendix/w26856 


\section{INTRODUCTION}

Regulation is often justified by the gains to the public that come from outcomes such as cleaner water and air, safer travel, less dangerous products, and more honest advertising. The costs of regulation are borne by the firms that must comply with them. Costs can be roughly categorized into two sets: physical operational costs and compliance risks. In the former category are the direct costs related to regulation's mandated changes (relative to what firms would otherwise do) in production, distribution, or sales practices. In the latter category are the indirect costs of bearing the uncertainties related to the way regulation is created and enforced. For example, since the 1970s, a broad trend in regulation has been for regulators to increasingly rely on "guidance" rather than formal rulemaking in setting regulatory standards (DeMuth 2016, Epstein 2016, Calomiris 2018), which observers believe has increased regulatory compliance risk. Guidance is attractive to regulators because the absence of formal rules gives them greater flexibility in implementing regulation, but of course, that same flexibility implies greater uncertainties for firms about how regulation will evolve and precisely what they will be held accountable for doing or not doing. Such uncertainty may in turn prevent firms from undertaking attractive investments due to the fear of an unforeseen regulatory response. We believe that our focus on understanding the impact of regulations as operating through one of these two channels - operational costs versus compliance risk - is novel to the literature.

Although many observers often express the belief that regulation is costly to firms both through its operational burdens and its compliance risks, research has not made much progress in measuring these costs, or even demonstrating that, in general, regulations are costly to firms. ${ }^{1}$

\footnotetext{
${ }^{1}$ Regulation sometimes serves special interests, and in particular, regulated firms, so it is not obvious that discussions of regulation are indicative of costs to firms rather than benefits. For example, Benmelech and Moskowtiz (2010) show that usury laws benefitted incumbent, low-risk firms by making it harder for entrants to compete with them. See also Peltzman (1965, 1976), Stigler (1971) and Kroszner and Strahan (1999) on the private
} 
For example, the Trump Administration claims that deregulation has been an important contributor to the acceleration of growth in the years since Trump's 2016 election, but there is no hard evidence to quantify whether that is true, or if so, how much of that growth should be attributed to deregulation. Furthermore, it is unclear whether whatever gains have come from less regulation are a consequence of lower operational costs or of reduced compliance risks. The distinction is important because, to the extent compliance risk is costly, important implications for regulatory reform may follow - for example, the need to restore the importance of formal rulemaking in the regulatory process.

Our goal in this paper is twofold. First, we address the regulation measurement issue by proposing a novel text-based measure derived from corporate earnings calls. We discuss this momentarily. Second, we investigate the channels via which regulatory exposure impacts corporate performance. Towards this end, we develop two hypotheses that serve to distinguish the empirical implications of regulatory exposure depending on whether it reflects increased compliance risk or increased physical operational costs. Both kinds of regulatory exposure discourage growth, but they have different implications for other variables. Hypothesis 1 states that increased compliance risk should be reflected not only in lower growth but also in higher future expected stock returns and lower leverage (defined as the ratio of debt to the market value of assets). Ceteris paribus, higher risk causes firms: to reduce investment, resulting in lower growth; to reduce leverage as the likelihood of distress makes the tax advantage of debt less attractive; and to compensate equity investors more for bearing more risk. Hypothesis 2 states

\footnotetext{
interests served by regulation. It is also important to recognize in some contexts that the regulation of one firm may benefit a firm in a different industry. For example, as we discuss further below with respect to utilities regulation, firms that use energy may benefit from greater regulation of utilities. Furthermore, regulation can be beneficial to both society and regulated firms, for example, if it positively affects the demand for their products by creating a more credible commitment to greater product quality. In general, however, to the extent that regulation constrains firms' actions rather than improves interfirm coordination, Le Chatelier's principle should hold: adding a constraint to the firm should be a source of cost. Our results confirm that, as a rule, regulatory exposure is costly to firms.
} 
that increased physical costs should be reflected in both reduced growth and (most directly) in reduced profit margins, but not in higher expected returns or reduced leverage. ${ }^{2}$ Ex-ante knowable costs should not impact corporate performance through risk-based channels, such as higher future stock returns or a higher likelihood of distress. We return to these hypotheses, summarized in Table 1, in our discussion of empirical findings.

Ours is not the first paper to use textual data for the measurement of regulation. Several recent studies make use of the data produced by the Mercatus Center at George Mason University (GMU), which tracks the word flow of the federal government's formal rule making, and has devised a means of attributing the relevance of that word flow at the sectoral level in the economy. ${ }^{3}$ This approach results in a panel dataset, defined for each sector and each year, that measures the growth in regulatory words, which can be used to gauge how differences in the amount of regulation over time and across sectors affect firms. The top panel of Figure 1 shows the GMU measure as an annual average across all economic sectors.

Although these data may be useful for many purposes, there are several major problems with them as measures of regulatory costs to firms. First, the widespread use of regulatory guidance as a tool is a major problem for this approach because guidance is not included in the Code of Federal Regulation. Second, state-level regulation is not included in this measure. Third, regulations can have different costs for different firms. Regulations that increase operating cost or compliance risk may create a comparative advantage for large firms (which can manage those costs better), thus boosting their ability to compete. Or a regulation may favor some aspect of one firm's business strategy relative to its competitors. Fourth, some regulatory changes

\footnotetext{
${ }^{2}$ A simple model: A competitive firm with convex production costs solves $\max _{\mathrm{q}} p \times q-c(q)$. At the optimum, the price of good is $p=c^{\prime}(q)$. If regulation increases $c^{\prime}(q)$ at all $q$ without impacting $p$, with $c^{\prime \prime}>0, q$ needs to fall. ${ }^{3}$ Al-Ubaydli and McLaughlin (2017) have examined regulation (at the industry-year level) through the lens of the amount of words published in the Code of Federal Regulations.
} 
constitute a reduction in regulation rather than an increase, but a simple counting of words does not distinguish actions that increase regulation from those that decrease it. Fifth, counting words ignores differences in the importance of regulatory word flow. This is especially a problem for gauging changes over time related to attempts at regulatory reform. For example, in the first year of the Trump Administration, the total growth in the amount of word flow as measured by the GMU data was identical to the average for each year of the Obama Administration. This may reflect a "bureaucrats-at-keyboards" phenomenon: a given number of federal employees hired to write regulations will produce a constant number of typed words per year, irrespective of whether those words are important. In times of deregulation, but with a constant growth of the bureaucratic workforce, the importance of regulatory word flow (on a per-word basis) diminishes, and measures based on calculating the number of words will miss that diminution.

Measures that assess regulation via the requirements it imposes - for example, the number of regulations passed with high estimated compliance costs, compiled by George Washington University (GWU), and reported as an aggregate time series - show a precipitous decline in regulation in the first year of the Trump Administration. This is shown as the solid line in the top panel of Figure 1. The contrast between the two aggregate regulatory measures in the top panel of Figure 1 suggests that the GMU total word flow method is particularly prone to understate changes in importance that are due to sudden changes in Administration philosophy. Clearly, the two measures provide dramatically different pictures of regulatory change in 2017.

While analyzing regulatory text directly is a promising research area that has yielded important insights, we take a different approach. We apply natural language processing (NLP) methods to a corpus that inherently filters the word flow related to regulation on the basis of its importance. Specifically, we undertake an NLP analysis of the transcripts of the earnings calls of 
publicly traded corporations. Earnings calls are quarterly opportunities for stockholders to hear from and question management about all the important influences on the values of companies. Given the limited duration of the earnings calls - they last about one hour - if management and investors use the scarce resource of time to discuss regulation, that is a reliable indicator of its importance. Furthermore, since time is scarce for all earnings calls, the methodology should work equally well for identifying important regulatory issues across all industries.

Because we analyze each company's earnings calls separately, if the same regulation favors one company and harms another, our measure will capture such differences in regulatory exposure. For example, utility regulation that reduces energy costs may harm utilities but help firms that use the energy produced by utilities. Indeed, we find some evidence that this is true.

Earnings calls also permit investors to question management, which means that important aspects of regulatory costs that may be neglected or exaggerated in management's presentation can be raised by investors in their questions. We find that the presentation and question and answer (Q\&A) portions of earnings calls both forecast firm-level fundamental outcomes, but only the Q\&A portion of calls is statistically significant for one-month ahead stock returns. This suggests that focusing only on the scripted management language found in 10-Ks misses an important source of information about the impact of regulations on firms.

For each earnings call, we construct separate measures for the management presentation and Q\&A parts of the transcript. Our preferred measure of regulation is NetReg, which captures both mentions of regulation and its direction: positive (negative) NetReg indicates greater (lesser) regulatory burden. As we discuss further below, and illustrate in the middle panel of Figure 1, our directional measure of regulation provides a dramatically different picture of regulation than one would get from just measuring the frequency of the use of regulation-related words in 
earnings calls, or measuring the quantity of word flow in government publications related to regulation. To measure the direction of regulation, we introduce two new word lists that are associated with increasing and decreasing regulatory burden, respectively. As a benchmark, we also construct a measure that captures the sentiment score of the transcript as a whole (AllSent). Sentiment is measured using the Loughran and McDonald (2011) sentiment dictionary.

As we discuss further below, our measure of regulation captures not only new rules and guidance created by all the relevant domestic and foreign government sources, it also captures how regulations are enforced for individual firms, and how particular firms experience changes in both rules and their enforcement over time. Indeed, a simple analysis of variance, reported below, suggests that the majority of variation that our measure captures is "within-firm" variation, rather than changes that are common across firms within a particular sector, or differences across firms that are constant, or variation across time that is common across all firms. Almost all of the variation our measure captures reflects idiosyncratic nuances in the changing ways that regulations are imposed on a particular firm, though our measure also reflects occasional economy-wide regulatory shocks.

Our results indicate that more regulation has major negative implications for the future growth and profitability of firms, that more regulation forecasts lower future firm leverage, that both compliance risk and physical operational costs are channels through which regulation affects firms, and that compliance risk is likely the more important of the two channels. We also find that regulation has fewer negative consequences for large firms than for small ones (see also Davis 2017). This result is consistent with a large literature on the political economy of regulation that sees regulation as less harmful to large firms because of their superior ability to lobby or the economies of scale in managing the operating costs and compliance risks associated 
with regulation, which in turn implies consequent competitive advantages of large firms over small firms that arise from greater regulation. ${ }^{4}$ Furthermore, we use topic modeling to analyze different contexts in which regulatory exposure might occur, for example in discussions of M\&A activity or of FDA oversight, and show that topical context of regulation also matters for firmlevel outcomes. Regulatory discussion by firms is multifaceted and a single measure of regulatory exposure is unlikely to convey all relevant information. The introduction of the NetReg measure and the demonstration that it is an important forecasting variable for future firm operating outcomes are the major contributions of this paper.

\section{A. Connections to Literature}

Davis (2017) is a closely related study to our paper. He tracks mentions of "regulation" in firms' 10-Ks. But he does not construct a measure analogous to ours that captures increases and decreases in regulation. If management wishes to avoid inconvenient discussions relating to compliance problems, then those discussions may be absent from 10-Ks. Similarly, management may blame regulation for its own failings. ${ }^{5}$ Thus, the carefully prepared $10-\mathrm{K}$ presentations about regulation by firms may contain biases that understate or overstate the consequences of regulation, especially if regulatory talk reflects changes in firms' performance.

Like us, Simkovic and Zhang (2020) propose an innovative measure of regulation that is not based directly on government regulatory texts. They quantify regulation at the industry-year level by tallying up the number of employees whose work has to do with regulatory compliance. This is a direct measure of the physical cost of regulatory compliance. They find that present

\footnotetext{
${ }^{4}$ Important theoretical contributions include Olson (1965), Stigler (1971, 1988), Krueger (1974), and Peltzman (1976). For discussions of the advantaged role of large firms in the regulatory process in finance, see Calomiris and Haber (2014), Chapters 7-8, Kirilenko et al. (2014), Gordon and Rosenthal (2016), and Libgoer (2020).

${ }^{5}$ Given this possibility, it is important to see whether regulation is a predictable consequence of firm underperformance. We discuss this in Section 4 below, where we find that our preferred measure of regulation is not a forecastable consequence of firm performance.
} 
industry-level regulation negatively predicts future firm-level employment, and find, as do we, that the effect is more pronounced for smaller firms. The focus of their study, however, is on industry entry: more heavily regulated industries experience more new entrants. Our papers differ in that our regulation measure is at the firm-level, and the focus of our empirical analysis is on firm-level outcomes. As Table 2 shows, our textual measures of regulation from earnings calls displays almost no correlation with the Simkovic and Zhang (2020) industry-level measure based on physical compliance cost. This is because the majority of variation in our regulatory measure reflects within-firm, and not macro or industry-wide, changes in regulatory exposure.

Hassan et al. (2019) study the effects of political risk on firm performance. They quantify the share of earnings calls devoted to discussing political risk by counting the number of political words that occur in the vicinity of words that are synonymous with "risk" or "uncertainty". This variable, PRisk, is negatively related to contemporaneous changes in investment, capital expenditure, employment, and sales growth (their Table V). They also introduce a variable, PSentiment, that measures Loughran and McDonald (2011) sentiment in the vicinity of political word mentions in earnings calls, and show that this variable is positively related to contemporaneous firm outcomes (Table VI). Although one might expect overlap between discussions of political risk and discussions of regulation, we find this is not the case. Our NetReg measure is analogous to PRisk, and for purposes of comparison, we also constructed a measure that we label RegSent, which is very similar to PSentiment (except we measure sentiment in the vicinity of regulatory words, and PSentiment measures sentiment in the vicinity of political words). ${ }^{6}$ As Table 2 shows, NetReg and PRisk are practically uncorrelated, as are

\footnotetext{
${ }^{6}$ In an earlier draft of this paper, we reported results for RegSent as an alternative indictor of regulation. Given that this measure appears to be noisier than our preferred measure, NetReg, we have dropped it from the current draft.
} 
RegSent and PSentiment. ${ }^{7}$ Indeed, out of the top 20 prominent cases of political risk discussions in earnings calls highlighted in Hassan et al. (2019), only one (Nanogen, Inc.) brings up matters potentially pertaining to regulation. Although PRisk and NetReg are largely unrelated in the earnings calls, Hassan et al. (2019) show that risk factors related to government actions can have important consequences for firms. Our paper provides additional evidence of the importance of political risk, specifically from the perspective of regulatory risks not captured by their study.

Our main empirical specifications involve regressing future firm outcomes on present measures of regulation. In that respect, our empirical design is quite different from Hassan et al. (2019); they are concerned with contemporaneous outcomes, and we are concerned with future outcomes. Our approach reduces the potential for reverse causality, and makes it more likely that our observed results reflect the influence of regulation on firms' performance.

Whether the effect of regulations on future outcomes is causal or simply proxies for some unobserved firm heterogeneity, the forecasting relationship of present NetReg on future outcomes is still of interest to market participants, corporate managers, and regulators. We do, however, control for many other possible influences on future firm outcomes, and find that none of them drive out the forecasting power of present NetReg. Furthermore, we find that NetReg is not a predictable consequence of changes in past firm performance, but that NetReg does forecast future firm performance. We believe it is unlikely that NetReg merely proxies for unobserved heterogeneity; if that were so, it would have to be important unobserved heterogeneity that is unrelated to multiple dimensions of past firm performance, which seems unlikely.

We also perform a validation check on our measure to see if it is associated with identifiable exogenous changes in the regulatory environment. When President Trump took office, he

\footnotetext{
${ }^{7}$ We thank the authors of the Simkovic and Zhang (2020) and the Hassan et al. (2019) papers for sharing their data.
} 
consciously and vocally used executive orders, agency and cabinet appointments, and other tools to reduce regulatory costs borne by firms. Not only is this regime change visible in the time series of an aggregation of our firm-level measures, but we also are able to test whether the impacts of regulation diminish in the immediate aftermath of the Trump inauguration. Specifically, we test for whether the negative effects on all our dependent variables from discussions of regulation are diminished after Trump's inauguration, and we find that this is true for all the dependent variables, both for the presentation and question-and-answer portions of earnings calls. We believe the totality of the evidence suggests (but, of course, does not prove) a causal interpretation of regulatory influences on firms' performance. ${ }^{8}$

Our regulatory text measures can be downloaded at www.measuringregulation.com.

\section{DATA}

Our measures of regulation are derived from textual analyses of all quarterly earnings calls of publicly traded firms from S\&P Global's Transcripts Data from 2009-2018. We merge these conference call data with pricing and accounting information for U.S. firms from CRSP and Compustat starting in $2008 .{ }^{9}$ From CRSP, we collect daily stock returns, number of shares outstanding, and trading volume for firms traded on the NYSE, Nasdaq, and Amex. From

\footnotetext{
${ }^{8}$ It is conceivable that firms might discuss regulation a year ahead of anticipated bad performance in an attempt to shift blame for reduced growth or profitability away from themselves. That possibility would work against a causal interpretation of a positive coefficient on NetReg in the results reported below. However, this "cheap talk" interpretation of our evidence implies that when one divides NetReg into its positive (more regulation) and negative (deregulation) components, the positive components (i.e., attempts to shift blame) would drive the results as managers have no incentive to falsely give deregulation credit for their own successes. In unreported results, we can reject the cheap talk interpretation of our results because, when one distinguishes between mentions of increasing and decreasing regulation, for most outcome variables, coefficient values are not significantly different; for sales growth and asset growth, the effects of mentions of decreasing regulation have larger magnitudes.

${ }^{9}$ We use a mapping provided by SP Global which associates an earning call's company identifier, ciqCompanyID, to Compustat's company identifier, gvkey. While there are instances where a gvkey is associated with multiple ciqCompanyId's (this happens for $4 \%$ of all gvkey's), the gvkey-date to ciqCompanyId-date mapping is unique (except for 4 firm-quarter observations which do not impact our results). We require that observations in S\&P Global have valid CRSP PERMNO and Compustat gvkey identifiers.
} 
Compustat, we obtain quarterly information on firm fundamentals. We exclude financial services firms (SIC codes beginning with 6) because performance measures, such as sales growth, for financial services firms are non-comparable to other firms. The following summarizes our data:

\begin{tabular}{|l|l|}
\hline Firm-quarter observations from Compustat and SP Global & 75,350 \\
\hline Firm-quarter observations with an earnings call that mentions regulation & 27,893 \\
\hline \% firm-quarters for firms that never had an earnings call mention regulation & $10.2 \%$ \\
\hline
\end{tabular}

Our primary measures of firm fundamentals are annual sales growth, annual asset growth, leverage (current liabilities and long-term debt over total assets), and operating (operating income over sales) and gross margins (sales minus cost of goods sold over sales), and annual changes in margins. We allow the consequences of regulation to depend on firm size. To measure the size of the firm, we use log sales over the quarter associated with the earnings call, with sales measured in millions of dollars.

All variables are measured relative to the quarter associated with the earnings call. As an example, for the quarter ending on June 30, 2012, Apple had its earnings release and conference call on July 24, 2012. All growth numbers are then relative to June 30, 2012.

Because not all earnings calls discuss regulation, we introduce a NoRegulat dummy variable that equals one for firms that have mentioned regulations in some earnings call in our sample, but not in the present one, and is zero otherwise. Some firms in our sample never mention regulations in any of their earnings calls; for such firms we introduce a dummy variable NeverRegulat, which is set to one for all of their firm-quarters.

To study the implications of regulation for stock returns, we examine returns, both in excess of the risk-free rate (1-month T-bill) and risk-adjusted (using the Fama-French 5-factor plus momentum), over 1-, 5-, and 22-trading days following the earnings call. Factor loadings used to calculate abnormal returns and alphas are estimated over a window from 252 to 31 trading 
days prior to the earnings call; for abnormal returns, the training window alpha is assumed to be zero. Returns are measured from the closing price of day $t$ (the date of the conference call) for calls occurring prior to 4 PM New York time and from the closing price of day $t+1$ (the following trading day) for calls occurring at 4 PM New York time or afterwards. This timing ensures that our future returns are not contemporaneous with the information revealed in the earnings call. Contemporaneous returns are either from day $t-1$ to day $t$, or from day $t$ to day $t+1$, depending on whether the call is pre- or post-4 PM. For our Apple example, the July 24, 2012 conference call took place after 4 PM New York time. The 22-day return is measured from the close of July 25, 2012 to the close of August 24, 2012. The estimation window for the calculation of alphas and risk factor loadings runs from July 25, 2011 through June 8, 2012.

To mitigate the influence of outliers in our regression analysis, we winsorize standardized unexpected earnings and log turnover (see Section IV.B), as well as sales growth, asset growth, leverage, operating margin, gross margin, operating margin growth, gross margin growth, and

SG\&A expense, at the two percent level (impacting 4 percent of the observations). We also tried winsorization at the one percent level, which resulted in nearly identical results. Excluded from all firm performance regressions are firm quarters with missing values for total assets, or sales that are missing or are below $\$ 5$ million. These quarters represent $21 \%$ of the sample. Table 5 summarizes the variable definitions, and Table 6 provides summary statistics.

\section{Measuring Regulation}

Our text analysis is performed on the earnings call data set obtained from S\&P Global. Before analyzing the calls, we perform the following cleaning steps: convert all words to lowercase; take out whitespace; remove stop words; tokenize and stem all words. For the sentiment analysis described below, we perform word negation, following the algorithm in Das 
and Chen (2007), which appends the string "_NEG" to all words in a sentence which follow an English language negation word, such as "don't" or "not". Word negation was performed prior to all other cleaning steps. In our sentiment analysis, we ignore negated sentiment words.

Our measure of regulation, labeled NetReg, can be positive or negative. Negative values indicate reduced regulation (or deregulation) and positive values indicate more regulation. To construct this measure, we begin by separately searching the presentation and the Q\&A parts of each quarterly transcript for the word root "regulat," which identifies the words that indicate the presence of a discussion of regulation (regulate, regulated, regulation, regulator, deregulate, etc.). We only focus on sentences mentioning regulat as well as one of a set of regulatory Concept words, to avoid instances of the use of regulat in other contexts (like engineering applications); we refer to such sentences as regulatory sentences. Focusing on regulatory sentences, as opposed to all sentences with regulat, has a minor effect on our NetReg measure. A further explanation of this filter and the list of Concept words are in the Online Appendix.

To gauge whether the discussion is one of increasing or decreasing regulation, we identify "Increasing" or "Decreasing" words that co-occur in the same sentence as regulat and convey a sense of increasing or decreasing regulatory exposure, respectively. These words are listed in Table 3 in order of their frequency of occurrence. Examples of sentences in which regulat is accompanied by Increasing or Decreasing words are provided in Table 4. It was from reading the context of these, and many other, sentences that we were able to judge whether words convey a sense of increasing or decreasing regulatory exposure. For example, it is not clear on an a priori basis whether the word "adapt" should be considered an Increasing word, a Decreasing word, or neither. By reading transcripts one discovers, however, that "adapt" is often used to indicate the need for a firm to adapt to an increased regulation; if regulations did not increase, there would be 
no need to adapt. Two examples illustrate the point: "We are well prepared to adapt to the changing legislative, regulatory and economic environment."; "Of course we're adapting our business model to the reality of regulation as it exists through the FDA [Food and Drug Administration]". More examples are in the Online Appendix. We emphasize that the choice of words indicating increasing or decreasing regulation was made by us prior to conducting the regression analysis in Section 4.

Our NetReg measure takes all regulatory sentences in the Presentation and Q\&A sections, respectively, calculates the difference between the number of Increasing and Decreasing regulatory words occurring in those sentences, and divides by the total number of words in these sentences after stop words have been removed, i.e.

NetRegS

$$
=\frac{N_{S}(\text { Increasing regulatory words })-N_{S}(\text { Decreasing regulatory words })}{N_{S}(\text { All words })},
$$

where $S \in\{P, Q A\}$ refers to the section of the call, and $N_{S}(\cdot)$ counts the number of occurrences of a particular word group in regulatory sentences of section $S$, excluding stop words. A higher (lower) value of NetReg implies a higher (lower) regulatory burden. Table 4 shows a set of sample sentences, along with the number of Increasing, Decreasing, and Concept words in those sentences. Generally, the prevalence of Increasing and Decreasing words captures the regulatory tone of each sentence. Our simple filter does a good job of (a) identifying meaningful regulatory references in earnings calls, as well as (b) identifying the directionality of the reference. Furthermore, it should be noted that our regulatory measurement procedure is extremely straightforward to implement, once the list of words in Table 3 is available.

We regard the use of subjective judgment in constructing the lists of Concept, Increasing, and Decreasing words as unavoidable for a simple reason: in the context of measuring regulation's 
impact, it is very challenging to use supervised learning techniques to identify these words. A natural supervised technique would be to infer Concept, Increasing and Decreasing words by identifying combinations of words that tend to result in positive or negative stock returns at the time of the earnings call. ${ }^{10}$ The problem with this approach, however, is that there are many important high-frequency influences, other than regulation, on stock prices that are revealed in the earnings call, and thus the effect of regulatory mentions on the contemporaneous stock return may get swamped by these other factors; furthermore, it is not a priori obvious whether more regulation is good or bad for stock prices. One could ask human experts to hand code earnings calls as indicative of increasing or decreasing regulation, and then use supervised techniques to extract associated word combinations. We see our Increasing and Decreasing word choices in Table 3 as effectively equivalent to this approach.

We also construct two measures based on the sentiment of the text in the earnings call. We use the Loughran and McDonald (2011) (LM) sentiment dictionary to identify positive and negative sentiment words in the earnings calls. We define two sentiment-related measures for each part (Presentation and Q\&A) of each call. The first of these, RegSent, which we constructed for purposes of comparison with other studies' measures, computes the sentiment score for each sentence in which regulat appears together with a Concept word after dropping stop words, i.e.,

$$
\text { RegSentS }=\frac{N_{S}(L M \text { positive } \text { words })-N_{S}(L M \text { negative words })}{N_{S}(\text { All words })} .
$$

The second sentiment-related measure, AllSent, calculates the sentiment score for the entire presentation or Q\&A discussion of the earnings call, after removing stop words, i.e.,

$$
\text { AllSentS }=\frac{A_{S}(L M \text { positve } \text { words })-A_{s}(L M \text { negative words })}{A_{S}(\text { All words })},
$$

\footnotetext{
${ }^{10}$ Examples of this approach include Ke, Kelly, and Xu (2018) and Glasserman et al. (2020).
} 
where $A_{S}(\cdot)$ measures the number of occurrences of a particular word group in all the sentences of section $S$. AllSent does focus on regulation, but rather is useful as a benchmark for the effects of sentiment in general, against which to compare the effects of regulation captured in NetReg.

We recognize the challenges in measuring regulation. NetRegP and NetRegQA are not flawless measures: they can and will be improved by future researchers. The extent to which they are imperfect, but pertinent, measures introduces an errors-in-variables problem that works against us finding economically or statistically important results. Yet, as we show below, we do find that these measures are associated with large and statistically significant consequences for firms' performance. Our results likely provide a lower bound estimate for the impact of regulation on firms' outcomes because our measures of regulation are not perfect.

\section{A. Regulatory trends}

The middle panel of Figure 1 plots the time-series paths of $N$ etReg $P_{t}$ and $\operatorname{NetRegQ} A_{t}$, which measure the quarterly equal-weighted average of NetReg for the Presentation and Q\&A segments of calls respectively. It is interesting that these two aggregate measures, plotted in Figure 1, are not highly correlated (with a correlation of only 0.09 ). Nor do they exhibit similar low frequency variation. This highlights the advantage of considering the contents of the Presentation and Q\&A sections separately, as we do. Management may not have an incentive to highlight all problems or risks, including those related to regulation, while investors' questions may be directed precisely at topics about problems or risks that management seeks to avoid.

The bottom panel of Figure 1 shows the proportion of earnings calls mentioning regulat in regulatory sentences. We see a clear, but small, upward trend. From 2010 to 2019 the proportion of earnings calls in which regulation is discussed rises from about $37 \%$ of the Calls to about $40 \%$ of them. The series has a large spike in 1Q2017, the quarter following the Trump election. 
Figure 2 plots the four sentiment-related measures, which differ according to (a) whether sentiment is measured only within the sentence in which regulation is discussed or in the entire earnings call, and (b) whether they are constructed from the presentation or the Q\&A portions of the earnings calls. Some highly interesting patterns emerge, which we believe are intuitively appealing, and which help to validate these measures. First, sentiment scores for the presentation portions are higher than the comparable sentiment scores for the Q\&A portions (that is, AllSent $P_{t}>$ AllSent $Q A_{t}$ and RegSent $\left.P_{t}>\operatorname{RegSent} Q A_{t}\right)$. Unsurprisingly, management tends to be more sanguine than investors during earnings calls. Second, the sentiment scores of sentences in which regulation is the topic tend to be lower than the earnings calls as a whole (that is, $A$ AlSent $P_{t}>\operatorname{RegSent} P_{t}$ and $\left.A l l \operatorname{Sent} Q A_{t}>\operatorname{RegSent} Q A_{t}\right)$. In other words, compared with other topics discussed in earnings calls, discussions of regulation, perhaps not surprisingly, tend to have more negative sentiment, whether it is discussed by management or investors. Third, sentiment scores are rising over time (sensible if improvements in economic activity are reflected in more positive sentiment), and similarly, there is some evidence that sentiment scores rose at the end of 2016 (the beginning of an acceleration in economic growth) for all four measures. Figure 3 compares our two approaches to measuring regulation, NetReg and RegSent. The measures are negatively correlated, as expected (NetReg $P_{t}$, the solid blue line, and RegSent $P_{t}$, the dotted red line, are correlated -0.62 , and $N e t R e g Q A_{t}$ and $\operatorname{RegSent} Q A_{t}$ are correlated -0.31). The definitions of the text variables are in Table 5, and summary statistics are in Table 6 .

\section{B. Case studies}

To build intuition for how our measures capture the regulatory environment faced by firms, Figure 4 plots NetReg and AllSent for Duke Energy, a large utility operating in many regulated markets. Duke devotes a relatively large fraction of its earnings calls, both in the presentation 
and the Q\&A sections, to discussing its regulatory landscape. Duke mentions regulations in most of its earnings calls, as can be seen from the nearly complete NetReg time series in Figure 4. We restrict attention to sections of calls that mention Increasing or Decreasing regulatory words from Table 3 five or more times in regulatory sentences. Sections with more regulatory modifier words are more informative about firms' regulatory exposures.

The August 7, 2013 Duke Energy earnings call contains the presentation section with the lowest $\operatorname{NetRegP}$ score among all presentation sections with five or more decreasing regulatory modifier words. We expect this call, therefore, to indicate an improving regulatory environment. Indeed, we first hear that "we [i.e., management] expect the second half of the year to be relatively stronger than the first half, primarily as a result of 3 items: First, constructive rate case outcomes." As a regulated utility, Duke periodically asks its state regulators to approve rate increases, and here expresses satisfaction with the allowed rate increases in this cycle. The company then discusses the regulatory approval of a decision to retire a nuclear power plant called Crystal River 3 on the west coast of Florida. It goes on to say that "2013 is an important year, with a number of regulatory proceedings to position the company for the future. We operate in constructive regulatory jurisdictions and have 5 approved or pending settlements with annual revenue increases of around $\$ 600$ million. This will result in less regulatory risk to the company, as well as more rate certainty for our customers." Note the emphasis on the risk aspect of regulation. The company does not mention the physical cost of its regulatory compliance, but rather the lower level of future regulatory risk. It goes on to say that given its "focus on resolution of near-term priorities and constructive regulatory outcomes, we have positioned Duke for low risk, primarily regulated growth through 2015." Duke is pleased about the low risk of its regulated growth. Finally, the company points out that "[1]ow load growth, new technologies, 
new regulations and ongoing cost pressures are just some of the forces that require new thinking and action. This includes innovation and technology deployment, continuous improvement [of] regulatory mechanisms." Again, the management of Duke is focused on, among other matters, evolving regulations and improvement of the regulatory mechanism.

There are two main takeaways from this. First, our scoring methodology does indeed identify this quarter as a very positive one for Duke Energy from a regulatory perspective. Second, Duke is concerned primarily about the risk associated with its regulations, as well as with the smooth functioning of the regulatory process. Nowhere is there mention of the explicit cost of regulation to the firm or of the resources the firm expends to manage its regulatory environment. Risk and a rational regulatory process are the primary concerns.

We also analyze regulatory mentions by American Axle, an automotive parts manufacturer, and by AutoNation, a national car dealer. American Axle and AutoNation face lower regulatory scrutiny than does Duke Energy. These two firms discuss regulations on their earnings calls very infrequently. When they do, it is often in response to unusual regulatory developments. In 2015, AutoNation discusses the increased "regulatory burden" of additional consumer protection regulations. In 2018, American Axle is concerned about an unanticipated regulator-mandated electricity rate increase. This example illustrates the strength of our method: we can identify infrequent, but important, regulatory mentions; obtaining similar information from other data sources is nearly impossible. These two case studies are analyzed in the Online Appendix.

\section{Analysis of variance}

In Table 7, we perform a variance decomposition of our NetRegP and NetRegQA measures, which allows us to identify how much of the variation in those measures reflects average sectoral effects, firm fixed effects, time effects, or the residual (within-firm variation, after controlling for 
all of those). We perform a Choleski-type decomposition which assigns to each category of influence (in the order reported in Table 7) a percentage of variance. We also compare these variance decompositions to similar analyses on other, sentiment-based, measures.

The results are striking. About 90 percent of the variation in $N e t R e g P$, and about 95 percent of the variation in NetRegQA reflects within-firm variation in earnings call discussions of regulation. Changes in rules for all firms that are enforced similarly should produce common effects across firms (time effects). Similarly, such changes in rules for a given sector should produce common effects for firms in that sector (sectoral fixed effects). We interpret the lack of importance of industry and time effects as implying the importance of idiosyncratic enforcement of regulations for particular firms. Furthermore, because firm fixed effects also explain little of the variation in our measures, we infer that regulatory enforcement varies importantly over time for firms in ways that are idiosyncratic. Despite this finding, there are occasional large systematic regulatory shocks, that our measures to capture and that we discuss further in an event study of the impact of NetReg around the Trump inauguration.

There are obvious examples of such variation, such as approval of new drugs, or anti-trust policies related to mergers. Our variance decomposition results suggest that such idiosyncratic events related to the changing enforcement of regulation are the main source of firm-level discussions of regulation. It is interesting to note the contrast between the variance decompositions for our $\operatorname{Net} \operatorname{Reg} P$ and $\operatorname{NetReg} Q A$ measures and the sentiment-based measures we construct for earnings calls. As Table 7 shows, within-firm variation contributes less to the variance of sentiment-based measures, suggesting that sentiment-based measures have a greater tendency to capture general news that is common across firms or across firms within a particular sector, or that is specific to a firm, but not time-varying. 


\section{Topics of regulation}

We investigate whether the importance of NLP measures of regulation varies according to the specific regulatory topic being discussed, where topics are identified as "clusters" of associated words. For example, it may be that when regulation is discussed in the context of some topics (e.g., mergers and acquisitions or M\&A) it has more or less importance than in the context of other topics (e.g., FDA approval of the company's experimental drug). After all, management references to regulation can mean different things: passing or repealing a new regulation, beginning or ending an investigation or an enforcement action, approving or denying a merger, approving or denying a drug's use, to name only a few. It is conceivable that some of these topical contexts are more important than others. Previous work has shown that sentiment can have very different meaning depending on topical context (Calomiris and Mamaysky 2019), suggesting topic modeling is an effective unsupervised-learning tool for economics applications.

For our topic model, we use Latent Dirichlet Allocation (LDA), first proposed by Blei, Ng, and Jordan (2003); Steyvers and Griffiths (2007) is a good primer. We estimate a ten-topic (more on this shortly) LDA model separately for the Presentation and Q\&A portions of our corpus. An LDA topic model is represented as two sets of distributions: each of the ten topics is a probability distribution over the words present in earnings calls (the topic-word distribution); and each document has a probability distribution over the ten topics (the document-topic distribution). In each case we use the Gibbs sampling implementation from the topicmodels package in R, with 2,000 iterations. We estimate each model using the document-term matrix derived from 41-word windows centered on the occurrence of the string regulat in either the Presentation or Q\&A section of calls. The 41-word windows are formed after stop words and 
some other common words are removed. ${ }^{11}$ We use these longer windows (rather than looking only at the sentence level) to have more context for the LDA topic estimation. The outcome of the topic model estimation for each section consists of the topic-word distributions, as well as document-topic distributions, for the Presentation and Q\&A sections of each call. We refer to the two topic models corresponding to the Presentation and Q\&A sections as the base models.

It is well known that LDA is a non-deterministic algorithm, e.g., Ke, Montiel Olea, and Nesbit (2020), and different LDA estimations applied to the same corpus can result in different topic models. To ensure that the base topics are robust, we perform an additional 200 LDA estimations: 100 for the presentation section and another 100 for the Q\&A section. For each base model and for each of the associated 100 evaluation runs, we recursively match evaluation run topics with each base model topic. This procedure, detailed in the Online Appendix, shows that many of our base model topics are extremely robust across all 100 evaluation runs, with the best matched evaluation topic almost identical to the base topic. Among the robust topics, several turn out to be similar to each other, and we group these together for our empirical analysis. Finally, there are two groups of topics (one in Presentation and one in Q\&A) which are not stable across LDA runs, and we group these topics together as well.

More details about our base topic models, the logic for how we name them, their topic-word distributions, their evolution over time, the LDA stability analysis, and the grouping methodology are in the Online Appendix.

Table 8 summarizes the topic model we use for the Presentation and Q\&A sections of the earnings call corpus. The top panel of the table shows that six topics (FDA, Fins, Legalese, $M \& A$, Margins, and $U t i l)$ are stable and distinct enough that they are used on a standalone basis

\footnotetext{
11 These words include: regulat, regul, regulatori, question, year, will, also, go, s, now, can, said, among others.
} 
in our empirical analysis. The ProdMkt-Client group combines two stable, but similar, topics.

Finally, the Euro-Legalese2 group combines two topics which are unstable across LDA runs, and represent effectively a residual topic category. Each row in the top panel shows the average document topic probability weights across calls on a particular topic group (i.e., the rate of topic incidence), as well as a list of each group's words with the highest probability weight.

The bottom panel of Table 8 show the same analysis for the base Q\&A topics. There are four distinct and stable topics (FDA, Fins, $M \& A, N e g$ ) which are used in the empirical analysis on a standalone basis. One topic group, ProdMkt-Client-EuroComp, is composed of relatively stable topics that are have high similarity to one another, and the other topic group CorpFin-UtilMargins is unstable across evaluation runs and represents the residual topic category for the Q\&A earnings call sections. The average group probability across all Q\&A sections in our corpus and the highest probability words in each topic group are shown in the rows of the panel.

We thus prune our original ten topics to eight Presentation and six Q\&A topic groups. In the next section, we use these topical groups to decompose our NetReg measure to understand how the context of regulatory discussion affects firm outcomes.

\section{EMPIRICAL FINDINGS}

In this section, we divide our discussion into six parts. First, we present our results which examine the effects of NetReg on future values of sales growth, and other dependent variables, including asset growth, leverage, and margins, using a variety of control variables. We explore differences in those results for large and small firms and perform other robustness tests on our specifications. We find that regulation negatively affects firms' sales growth, asset growth, leverage, and margins. The effects are larger for small firms. Second, we show regulation discussions in the Q\&A section of Earnings Calls have positive effects on future excess returns. 
Third, we expand the time-horizon over which the effects on firm performance and leverage may occur, and we find that most effects of regulation news on future performance affect performance over a two-year response horizon; the exception is leverage, where negative effects from regulation continue to grow beyond that time horizon.

Fourth, we show that NetReg is not forecasted by lagged measures of firm performance or by lagged stock returns. We interpret NetReg, therefore, as measuring unforecastable regulatory news. This implies that the usefulness of NetReg for forecasting future sales growth, leverage, and other firm performance measures likely reflects exogenous regulation news (unrelated to lagged characteristics or contemporaneous control variables), rather than predictable responses of regulatory events to changes in firm performance. Another commonly used text-based measures of earnings calls (our general sentiment indicator for the Earnings Call, AllSent), in contrast, is predictable by lagged firm characteristics. The fifth part of our analysis looks at the impact of NetReg on all of our outcome variables in the year before and the year after the Trump election. We find that the negative effect of NetReg on firm outcomes diminishes after Trump takes office, which argues for, though does not definitively prove, a causal interpretation.

Finally, we extend our analysis to measure differences in the importance of topical context for our NLP measures. Our LDA topic model allows us to identify which aspects of regulatory news have the largest effects on firm performance. We find that regulatory discussions related to mergers and acquisitions $(M \& A)$, actions by the Food and Drug Administration $(F D A)$, the regulation of financial institutions (Fin), and utilities regulation (Util) stand out as areas of particularly large influence, and we explore possible interpretations of these topic areas. 
After reporting these various findings, we consider the implications of our findings from the perspectives of Hypotheses 1 and 2, and therefore, about the likely relative importance of compliance risk and physical operational burdens for explaining our findings.

\section{A. Effects of regulatory tone on firm performance measures}

Our core analysis is a panel regression with firm-quarter observations, where we study how future firm outcomes depend on NetReg and AllSent. We control for numerous potential influences on future outcomes, including lagged firm size (log sales), lagged annual firm growth, leverage, or profitability, industry-level measures of firm regulation calculated as equal-weighted averages in the firm's 2-digit SIC industry over the prior 90 days, dummies indicating absence of regulatory mention, and industry fixed effects. ${ }^{12}$ The basic specification for firm $i$ in quarter $t$ is

$$
G_{i, t \rightarrow t+4}=a_{j}+b \times C T_{i, t}+\left[b_{1} \times C T_{i, t} \times I_{i, t}\right]+c^{\top} X_{i, t}+\epsilon_{i, t \rightarrow t+4},
$$

where $G_{i, t \rightarrow t+4}$ is the firm variable of interest (e.g. future sales or asset growth, year-ahead leverage, etc.), $a_{j}$ is the 2-digit SIC industry fixed effect, $C T_{i, t}$ is the text-based "call tone" measure (NetReg or AllSent), and $X_{i, t}$ is the vector of the quarter $t$ control variables described above. In many specifications, $X_{i, t}$ will also contain the lagged dependent variable. In some specifications, we include the $C T_{i, t} \times \log (\text { Size })_{i, t}$ (i.e., $\left.I_{i, t}=\log (\text { Size })_{i, t}\right)$ interaction to study how the effect of our text measure depends on firm log sales. In all specifications that interact firm size with our regulatory sentiment measures, we demean log sales using the full-sample mean. All standard errors in (2) are clustered by 2-digit SIC codes and by quarter. ${ }^{13}$ Note that

\footnotetext{
${ }^{12}$ Time fixed effects would mask macro changes in the regulatory environment, like those coming from a new administration. Firm fixed effects would remove the impact of rare regulatory events, for firms like American Axle or AutoNation, which discuss regulations very infrequently, and only do so when the impact is material.

${ }^{13}$ These quarters are obtained from the Compustat variable datadate. For example, November 30 and December 31 will both be classified as being $4^{\text {th }}$ quarter observations.
} 
clustering by 2-digit SIC codes is more conservative than clustering by firm because the former allows for interfirm correlations within an industry, whereas the latter does not.

Table 9 provides detailed results on all the specifications used to analyze the forecasting relationship between lagged NetRegP and NetRegQA and year-ahead sales growth. Similarly detailed reporting of our results for other variables are in the Online Appendix. Table 10 summarizes the results for all our dependent variables. Table 10 normalizes effects by the standard deviations of the two NetReg measures, where outcomes are expressed in percentage changes for each of the dependent variables. Table 9 (and similar tables in the Appendix) report results in raw (not normalized) form.

Table 9 shows that, in both the Presentation and Q\&A sections, the two NetReg variables are associated with large and highly statistically significant effects on one year-ahead sales growth. ${ }^{14}$ The effect is robust to the inclusion of various controls. We begin with a discussion of the specifications that do not allow the effects of NetReg to vary by firm size, and that do not normalize for cross-industry differences. All the specifications include a NoRegulat (firm does not mention regulation in a given call) and a NeverRegulat dummy variable (firm never mentions regulation in the entire sample, see Table 5), which control for any selection bias associated with the presence of any mention of regulation in the earnings call.

As reported in Table 10, a one standard deviation increase in $\operatorname{NetRegP}$ forecasts a 1.6\%, i.e., 31.263 (coefficient estimate from $1^{\text {st }}$ column of Table 9$) \times 0.052$ (standard deviation of NetRegP), reduction in sales. The comparable reduction in sales using the coefficient value for

\footnotetext{
${ }^{14}$ Lagged sales growth is mildly autoregressive. In our sales growth regressions reported in Table 9, coefficients on lagged sales growth range from 0.07 to 0.08 . In a pooled regression with only lagged sales growth as the independent variable, we observe that lagged sales growth has a coefficient of 0.03 . This is consistent with Chan, Karceski and Lakonishok (2003) who document low persistence in sales growth and other measures of firm growth over similar horizons.
} 
NetRegQA in column (2) is $0.9 \%$, i.e., $-17.073 \times 0.054$ (standard deviation of NetReqQA). The negative coefficients on No Regulat and Never Regulat indicate that companies whose earnings calls do not mention regulation tend to have lower sales growth in the subsequent year.

Columns (3) and (4) of Table 9 explore differences in the sales growth consequences of NetReg that are associated with firm size, by interacting NetReg with the full-sample demeaned firm size. In both the Presentation and Q\&A sections of the earnings calls, there are positive coefficients on the interaction of firm size and NetReg; the effect is significant for the presentation section, and significant at the $13 \%$ level for the Q\&A section. Using both the simple coefficient values for NetReg and their interactions with size, for an average-sized firm, a one standard deviation increase in $\operatorname{NetReg} P$ is associated with a 2.2\%, i.e., -43.030 (coefficient in column 3) $\times 0.052$, decline in sales growth, but at the $75^{\text {th }}$ percentile of size, the effect is a $1.7 \%$ decline in sales growth, i.e., $-43.030 \times 0.052+9.024$ (interaction coefficient in column 3$) \times$ $0.052 \times(6.789-5.626)\left(\right.$ difference between $75^{\text {th }}$ percentile and mean of size). For the largest firm in our sample (with log sales of 11.8 , which is 6.2 above the mean), there is actually a small positive effect of $0.7 \%$ of $N e t \operatorname{Reg} P$ on sales growth. At the $25^{\text {th }}$ percentile of size the effect is a $2.8 \%$ decline in sales growth, i.e., $-43.030 \times 0.052+9.024 \times 0.052 \times(4.403-5.626)$ (difference of $25^{\text {th }}$ percentile and mean size). The comparable computation for NetRegQA results in a $1.6 \%$ decrease in sales growth, i.e., -29.433 (coefficient from column 4) $\times 0.054$. At the $75^{\text {th }}$ percentile of size, the effect is a decline of only $1 \%$, i.e., $-29.433 \times 0.054+9.163$ (interaction term in column 4$) \times 0.054 \times(6.789-5.626)$. At the $25^{\text {th }}$ percentile of size, the effect is a decline of $2.2 \%$, i.e., $-29.433 \times 0.054+9.163 \times 0.054 \times(4.403-5.626)$. For the largest firm in the sample, the effect of NetRegQA on sales growth is roughly a positive $1.5 \%$, in line with the 
NetRegP finding. This confirms the common view in the regulation literature that large firms enjoy an economy of scale in dealing with regulation.

Columns (5) and (6) of Table 9 measure NetReg in a way that adjusts for any cross-industry differences at the two-digit SIC level, while also allowing its effect to vary by firm size. We adjust for cross-industry differences in NetReg by constructing two new variables, Ind. Adj. NetRegP and Ind. Adj. NetRegQA, which are the firm-level NetReg measures minus the 2-digit SIC industry average NetReg of the respective portions of earnings calls on that reporting date and over the prior 90 days (Ind. NetRegP and Ind. NetRegQA, see Table 5). The coefficients on Ind Adj. NetReg remain negative and highly statistically significant, and their magnitudes are similar to the unadjusted NetReg measures. For an average size firm, after taking out the industry-specific mean of regulation, the implied reductions in sales from standard deviation increases in Ind. Adj. NetRegP and Ind. Adj. NetRegQA are 1.5\%, i.e., -32.046 (coefficient from column 5 of Table 9) $\times 0.048$ (standard deviation of Ind. Adj. NetRegP), and 0.9\%, i.e., 18.376 $\times 0.049$, respectively. The industry average effects (Ind. NetRegP and Ind. NetRegQA) are also very large and negative. A standard deviation increase in Ind. NetRegP, reduces sales growth for the firms in the industry, on average, by $1.2 \%$, i.e., -64.050 (coefficient in column 5$) \times 0.018$ (standard deviation of Ind. NetRegP); a one standard deviation increase in Ind. NetRegQA reduces sales growth by $0.8 \%$, i.e., 38.662 (coefficient in column 6$) \times 0.02$ (standard deviation of Ind. NetRegQA). This industry effect is in addition to any effects of firm-specific deviations from the industry mean, which are captured by Ind. Adj. NetRegP and Ind. Adj. NetRegQA.

In columns (7) and (8) of Table 9 we also include the lagged value of the NoRegulat variable, which controls for the absence of regulat in the earnings call from a year before, as well as the one-year lagged value of NetReg. We control for NetReg from a year ago to see the extent 
to which the effect of NetReg in the present quarter on future sales growth is a manifestation of regulation already found in the past. We find that values of NetReg, beyond the most recent ones, have little effect on next year's sales growth.

In Table 10, we summarize (in Panels A through C) normalized results of the effects of a one-standard deviation change in NetRegP and NetRegQA on year-ahead changes in each of our seven firm performance measures (sales growth, asset growth, leverage, operating and gross margins, operation margin change, and gross margin change), and in Panel D, we report results for stock returns (described below). As a benchmark for comparison, we also include a general sentiment measure (AllSent) for the Presentation and Q\&A sections of the Earnings Calls, and show the impact of a one standard deviation change in this measure on the dependent variables. For our seven performance measures, Panel A reports results for the whole sample, without differentiating by firm size, while Panels B and C report magnitudes for small and large firms. ${ }^{15}$

Table 10 shows that $\operatorname{NetRegP}$ discussions have economically and statistically significant negative effects on six of the seven dependent variables. NetRegQA displays similar effects on sales growth, asset growth and leverage, but not on the margin measures. The magnitude of the effects of NetRegP on sales growth and asset growth are relatively larger than the effects on margins. All effects are uniformly larger for small firms than for large firms.

In results reported in Appendix Tables A43 and A44, we experimented with alternative functional forms to the simple linear treatment of NetReg in the results reported thus far. One alternative specification adds the square of NetReg to all the specifications. In some cases, the

15 If the coefficient on NetReg is $b$ and on the size interaction NetReg $\times$ Size is $c$, Panels B and C report $b \sigma_{N R}+$ $c \sigma_{N R}\left(\right.$ Size $\left._{p}-\overline{\text { Size }}\right)$, where Size $e_{p}$ is the $\mathrm{p}^{\text {th }}$ percentile of the size distribution in the full sample and $\overline{\text { Size }}$ is the mean size in the full sample, and where $\sigma_{N R}$ is the standard deviation of NetReg. The standard error of this size-adjusted coefficient is $\sigma_{N R}\left(\operatorname{se}(\hat{b})^{2}+\left(\operatorname{Size}_{p}-\overline{\operatorname{Size}}\right)^{2} \operatorname{se}(\hat{c})^{2}+2\left(\operatorname{Size}_{p}-\overline{\operatorname{Size}}\right) \operatorname{cov}(\hat{b}, \hat{c})\right)^{1 / 2}$ where $s e(\cdot)$ is the standard error of coefficient estimates and $\operatorname{cov}(\hat{b}, \hat{c})$ is the covariance of the $b$ and $c$ estimates. 
squared term was significant and positive (indicating a diminution of the linear effect), and in others it was significant and negative (indicating an increase in the linear effect). But the coefficients on NetReg are similar to the linear specification and the overall results are qualitatively the same to those reported above. Another alternative specification divides NetReg into its positive and negative component parts, which we define as IncReg, occurrences of increasing regulation, and DecReg, occurrences of decreasing regulation. The coefficient values for IncReg are typically negative and those for DecReg are typically positive. The null hypothesis that the effects of IncReg and DecReg are the same but of opposite sign is not rejected in most cases. Interestingly, the coefficients for the margin variables tended to be larger for IncReg, while those for DecReg were greater for sales and asset growth. One interpretation of these findings is that decreased regulation mentions are associated with a larger effect on compliance risk than increased regulation mentions (under the assumption that compliance risk affects sales and asset growth), while increased regulatory mentions have a larger effect on physical costs (which are more relevant for margins).

\section{B. Return regressions}

For our analysis of stock returns, we control for the log of market equity (in millions), the log of the book-to-market (BM) ratio (the log of book equity over market equity), and standardized unexpected earnings (SUE) defined similarly to Bernard and Thomas (1989). These variables are measured on the end date of the quarter corresponding to the earnings call. As in Tetlock, Saar-Tsechansky and Macskassy (2008), we control for abnormal excess returns on the day of the call and over the 21 trading days before the call. We also control for alpha, and log of share turnover defined as daily shares traded divided by shares outstanding on the day of the earnings call. The specification for the returns of firm $i$ on earnings call day $t$ is 


$$
R X_{i, t+\delta \rightarrow t+\delta+h}=a+b \times C T_{i, t}+c^{\top} X_{i, t}+\epsilon_{i, t+\delta \rightarrow t+\delta+h},
$$

where $h$ is either 1,5 , or 22 trading days, $\delta$ is either 0 or 1 depending on whether the call was pre- or post-4 PM, $R X_{i, t+\delta \rightarrow t+\delta+h}$ is either the excess or risk-adjusted return for firm $i$ over the ensuing $h$ trading days after the call, $C T_{i, t}$ is the conference call tone variable of interest, and $X_{i, t}$ is a vector of controls. In the contemporaneous version of the regression in (2), we drop log share turnover as a control variable, because of endogeneity concerns, as well as the day-of-call return itself (obviously). We report standard errors for the return regressions in (3), clustering by conference call dates and by 2-digit SIC codes. The results are reported in Panel D of Table 10.

We find that $\operatorname{Net} \operatorname{Reg} Q A$ (but not $\operatorname{Net} \operatorname{Reg} P$ ) has positive, large, and statistically significant effects on future excess and risk-adjusted abnormal returns in the 22-day period following earnings calls (the methodology to calculate returns is detailed in Section 2). We find negative, though not significant, impacts of NetReg on call-day excess and abnormal returns. ${ }^{16}$ Though we do not have power to reject the null for contemporaneous returns, the same-day negative returns and future positive returns due to NetReg are consistent with the risk explanation. Higher regulatory exposure makes investors demand higher risk compensation which is accomplished via lower stock prices on the day of the call, and higher future returns. We interpret the difference between NetRegQA and NetRegP effects on returns as indicating that questions raised by analysts about regulation are more relevant for measuring the importance of the discussion as news to the market about risk.

The evidence from returns that risk exposure increases when there is more discussion of regulation is confirmed by the leverage results. If increases in NetReg capture increased

\footnotetext{
${ }^{16}$ Tables A35-A40 in the Online Appendix report the details of these regressions for same-day and future returns (as well as the analogous regressions for RegSent). We also tried running one-day and five-day ahead regressions. The results are consistent with the 22-day results but are weaker. These results are available from the authors.
} 
compliance risk, then according to the traditional "tradeoff" theory of leverage - where firms trade off the gains from the tax benefit of debt against the expected cost of financial distress $-\mathrm{a}$ rise in risk should be associated with a decline in leverage. For leverage, the magnitudes of the effects are consistently greater for $N e t \operatorname{Reg} P$ than for $N e t \operatorname{Reg} Q A$.

It is also interesting to compare the results for NetReg against the benchmark of AllSent measures in Table 10. Not surprisingly, sentiment of earnings calls often has positive predictive relevance for stock returns and operating performance measures, and magnitudes are similar to those from regulation measures. But sentiment is a significant predictor of firm performance less frequently than is NetReg.

\section{Persistence of effects beyond one year ahead}

Our empirical findings thus far have focused on one-year ahead forecasts of sales growth, asset growth, margins, and leverage. But the magnitudes of the effects we measure could be misleading if these variables adjust with protracted lags to changes in regulation news. Does an increase in NetReg produce further declines in sales and asset growth, margins, and leverage in the next, or third, or fourth years, or a leveling off of the effects, or perhaps reversion? To address these questions, we use the local projections method of Jorda (2005) to calculate cumulative impulse responses to a one standard deviation shock in NetRegP and NetRegQA. This method is robust to data generating process misspecification and accommodates potential nonlinearities, as opposed to a traditional vector autoregression approach.

In Figure 5, we report impulse responses for sales growth and leverage. After two years the effect of a NetRegP shock on an average-sized firm's sales growth flattens out. The cumulative four-year effect on sales growth is about three times the one-year effect. For NetReqQA, the entire effect for an average-sized firm happens in year one, as the four-year cumulative effect is 
very similar to the one-year effect. We also calculate the impulse responses for a larger firm ( $75^{\text {th }}$ percentile by log sales) and find in both the Presentation and Q\&A cases it is smaller than the effect for an average-sized firm, as was to be expected given the results in Table 9. We conclude that $N e t \operatorname{Reg} Q A$ has a one-time, persistent effect on the level of sales, while NetRegP has a continuing effect over the next year or two. There is no evidence of reversals in either case.

Figure 5 shows a very different picture for the impulse response for leverage. As in the case of sales growth, there is no reversal in the impulse response. However, in the case of leverage, by the fourth year, the cumulative response is an order of magnitude larger than the one-year response, and after four years the decline in leverage does not appear to be flattening. This is true for both average-sized and large $\left(75^{\text {th }}\right.$ percentile) firms. This suggests that leverage adjusts much more slowly than sales growth to regulatory shocks. Furthermore, it shows that the long-run effect of regulation on leverage is comparable in magnitude to the long-run effects of regulation on sales growth and asset growth, and the long-run effect on leverage is substantially understated by the coefficient reported in Table 10. We are not confident reporting results beyond four years for the leverage impulse response (note that our data period is only a decade long), but we believe it is clear that leverage responses grow over time much more than sales growth responses. Impulse responses for other variables (reported in the Online Appendix) show similar results to those of sales growth: there is no protracted adjustment lag in any of the other dependent variables. In unreported results, we also found no persistence in effects from AllSent on firm performance measures.

\section{Is regulatory discussion forecastable by other variables?}

Next, we examine the question of whether NetReg itself is forecasted by firms' past operating performance, as measured by sales, asset growth, margins, and stock returns. A potential concern 
about our interpretation of our regulation measures as indicators of news is that discussions of regulation may reflect "cheap talk" by firms attempting to blame previous poor performance on regulation when in fact, poor performance reflects other influences. If that were true, we would expect problems in sales growth or profitability to predict mentions of regulation. If the NetReg measures capture news they should not be forecastable using prior firm performance.

The results of this analysis are summarized in Table 11, and the details are reported in the Appendix. As Table 11 shows, no lagged values of any firm performance measures are statistically significant forecasters of NetReg, either for the presentation or the Q\&A sections of Earnings Calls. In the Appendix, we also report adjusted R-squareds, which are around nine percent for $N e t \operatorname{Reg} P$ and three percent for $N e t \operatorname{Reg} Q A$ in all specifications. The regulatory discussion from the presentation section is more forecastable than the unscripted regulatory discussion from the Q\&A section. NetRegP and NetRegQA are predicted positively by their own lagged values (with NetRegQA much less so), and $\operatorname{NetReg} P$ is predicted negatively by firm size, which is a control in all our specifications. The lagged one-month risk-adjusted return has no forecasting power for NetReg. This is an important finding because it addresses the concern that discussions about regulation may reflect managerial cheap talk (e.g., poor stock market performance prompting managers or shareholders to talk more about regulation).

In summary, NetRegQA and NetRegP are mainly forecastable by their own past and NetRegP is related to firm size. Adjusted R-squareds are small. Other variables related to firm income measures or past stock returns have little forecasting power for NetRegP or NetRegQA.

As Table 11 shows, in sharp contrast, AllSent is predictable on the basis of lagged measures of firm performance, for both the Presentation and Q\&A sections of the Earnings Calls. As the reported results in the Appendix show, the AllSent dependence on lagged AllSent is much higher 
than the AR(1) coefficient for NetReg and adjusted R-squareds are also much higher for predicting AllSent (in the 30\% range for AllSentP and 13\% for AllSent $Q A$ ). This difference has important implications for interpreting the coefficients related to AllSentP and AllSentQA that are reported in Table 10. It would not be appropriate to interpret these as indicators of news, given that these variables are themselves somewhat predictable on the basis of prior firm performance. Of course, they are not entirely predictable, which likely explains why they still have consequences for post-Earnings Call returns.

It is also important to bear in mind that sentiment may affect future returns not as a risk measure but more as an indicator of firms' prospects that is not fully taken into account by market participants. Previous work has found both that sentiment scores from Earnings Calls have positive implications for returns indicative of positive earnings news (see Price, Doran, Peterson, and Bliss 2012) and also that sentiment measures contain information about future stock prices that is not fully taken into account in market responses to news (e.g., Calomiris and Mamaysky 2019; Glasserman, Li, and Mamaysky 2022). In other words, in contrast to discussions of regulation (where the specific topic is a conscious subject of conversation and is therefore indicative of priced risk), sentiment scores may not have been recognized in the past as a source of information by market participants. This may explain why post-Earnings Call returns are positively forecastable by AllSent.

\section{E. Validation test: Regime change after Trump's inauguration}

In previous analysis, we have shown that $N e t \operatorname{Reg} P$ and $N e t \operatorname{Reg} Q A$ are statistically exogenous (in the Granger sense) to firm performance measures. Here we confirm their exogeneity in the economic sense by performing a validation test. Recall that our NetReg measures, in the aggregate, show a decline when President Trump assumed office (Figure 1). We posit that this 
reflects his Administration's commitment to reducing the costs of regulation, which was reflected in various executive orders, public statements, and choices for heads of regulatory agencies and cabinet positions.

If our measures of regulation capture exogenous variation in regulation, as we have argued is plausible, then Trump's inauguration should produce a decline not just in the mention of regulation, but also in its costs to firms. We hypothesize, therefore, that Trump's inauguration should cause the coefficients reported in Table 10 to be diminished in absolute value.

We test that hypothesis by comparing the coefficients that measure the cost of regulation (as in Table 10) in the periods immediately before and immediately after Trump's inauguration (using data from January 1, 2015 to January 31, 2018 to capture these two periods). Within that time frame, we define pre-inauguration periods as those with dependent variables (using the timing convention of equation (2)), with starting dates prior to April 20, 2016. Given the oneyear length of the dependent variables, this starting date constraint ensures that at least nine months of the year captured by the dependent variable occur in the pre-inauguration period, since inauguration day was on January 20, 2017. Similarly, post-inauguration periods for the dependent variable have starting dates after October 20, 2016, which ensures that at least nine months of the relevant time interval for each dependent variable occur in the post-inauguration period. We drop dependent variable observations that begin between April 20, 2016 and October 20, 2016. Only firms with both pre- and post-inauguration observations in the January 2015 to January 2018 sample are retained for this analysis. We ran regression using the specification in (2) (similar to those reported in Table 10), but added a Trump inauguration dummy (i.e., $I_{i, t}$ is set to one for post-inauguration firm quarters), and interacted that variable with the coefficients on $\operatorname{NetRegP}$ or $\operatorname{Net} \operatorname{Reg} Q A$. 
Table 12 reports the results for this validation test. The first column of the table shows the coefficients on NetRegP or NetRegQA by itself for each of the dependent variables. These coefficients capture the pre-inauguration effects of these regulatory measures, and are generally comparable to those reported in Table 10. The second column of the table reports the interaction of the post-inauguration dummy and the coefficients on NetRegP or NetRegQA. The sum of the coefficients reported in the two columns captures the post-inauguration effects of these regulatory measures.

Strikingly, for every one of the dependent variables, in all the NetRegP and NetRegQA regressions, the point estimates reported in Table 12 imply a mitigation of regulatory impacts in the post-inauguration period. The magnitudes of the mitigations are large (sometimes even causing the total effect to fall to zero). In many cases, these effects also are estimated precisely (and are sometimes highly statistically significant). We believe this provides useful additional evidence of the validity of our NetRegP and NetRegQA measures as measures of exogenous variation in regulation.

\section{F. Relative importance of different topical contexts}

Using the LDA method for identifying topics related to regulation, we explore whether NetReg effects on dependent variables are different across topical categories. In our topicspecific specifications we decompose $\operatorname{NetRegP}$ and $N e t \operatorname{Reg} Q A$ into the portion coming from a given call's topical distribution. If $\phi_{i, t, \tau}^{P}$ is firm $i$ 's time $t$ Presentation section regulatory weight for topic $\tau$, then we include as regressors in our forecasting regressions the terms

$$
\left\{\phi_{i, t, 1}^{P} \times N e t \operatorname{Reg} P_{i, t}, \cdots, \phi_{i, t, 8}^{P} \times N e t R e g P_{i, t}\right\}
$$

for the presentation section, and analogously six such interacted terms for the Q\&A section.

Since $\sum_{\tau} \phi_{i, t, \tau}^{P}=1$ (and similarly for $\phi_{i, t, \tau}^{Q A}$ ), this specification encompasses our baseline model 
(since all the interacted terms could have the same coefficient). For example, we interact $N e t R e g P$ and NetRegQA with the document-topic probabilities for the M\&A topic in each section as a right-hand side variable, labeled $M \& A$ (Pres) * NetRegP and $M \& A(Q A) *$ $N e t R e g Q A$ in the table. If a call has a large $N e t \operatorname{Reg} P$ value but a low topical allocation to the M\&A topic, then the interacted variable will be close to zero. We then are able to discern how the topical context of NetReg affects future values of the dependent variable (e.g., sales growth). We report results for sales growth, asset growth, and leverage in Table $13 .{ }^{17}$

For both the Presentation and Q\&A sections, we find that the most significant topic areas with negative regulatory influence are M\&A and FDA. This makes sense given the potential importance of regulatory approval for mergers or new products. Euro-Legalese2 and Margins also display some negative effects in the presentation section. Financial regulation (Fins) shows a negative effect on leverage in the Q\&A section. Recall that we restrict our sample to nonfinancial firms so this finding is not mechanical. We interpret the effect of Fins on leverage of non-financial firms as perhaps implying a negative effect on borrowing firms from the regulation of financial firms (perhaps reflecting reduced credit supply effects from financial regulation).

We also observe a topical context with a positive coefficient: Util for asset growth and leverage. We investigated how this effect differed across firms of different types and found this

\footnotetext{
${ }^{17}$ In unreported results, we ran topical models similar to those reported in Table 13 for the three margin variables that show statistically significant responses to NetRegP in Table 10. The results were quite similar to those reported in Table 13. Specifically, the FDA, Fins, and Euro-Legalese topics were significant and negative in their interactions with NetRegP. The Margins topic interaction with NetRegP was negative and significant only for the change in gross margins, and zero for the other two margin variables. In the operating and gross margins regressions, the interaction of the Util topic and $N e t R e g P$ was not statistically significantly different from zero for the sample of nonutility firms, and the interaction of $\operatorname{NetRegP}$ and the M\&A topic was positive for the change in operating margin and zero for the gross margin and the change in gross margin. One explanation for the latter finding is that mergers create expenses; the possibility that a merger would not be approved might, therefore, be associated with an improvement in next year's change in operating margins because of absence of merger-related expenses.
} 
positive effect to be stronger for non-utilities, suggesting a positive effect of more utility regulation on utility customers. Regulatory impact on producers and consumers may thus differ.

Overall, these results confirm the view of regulation we presented in the introduction. Regulatory news can mean very different things (e.g., new prudential regulations on financial intermediaries, as opposed to drug or merger approvals, or utility price limits), and each of these can have different implications for different firms (e.g., consumers or producers of energy). The analysis of topical context reinforces our view that a text-based measure of regulation like NetReg can capture a wide variety of influences. In future work, it will be useful to think of ways to distinguish these various kinds of regulatory influences from one another to see how, for example, the effects of regulatory standard setting differ from the effects of regulatory enforcement actions, or how discussion of existing regulations differs from discussion of anticipated future regulations. ${ }^{18}$

\section{G. Channels: compliance risk vs. physical compliance costs}

The combination of empirical findings reported here (that regulatory news predicts significant reductions in growth and leverage, an increase in expected future returns, and smaller negative change in operating margins) contains elements that confirm both Hypothesis 1 and Hypothesis 2 about the channels through which regulation affects firms (reflecting a combination of compliance risk and physical operational costs). Nevertheless, we believe the findings suggest the relative importance of Hypothesis 1 (consequences of increased regulatory compliance risk), given that the magnitudes of the long-run effects on growth, leverage and returns are large

\footnotetext{
${ }^{18}$ A similar point about the importance of topical context in earnings calls is made by Meursault et al. (2021).
} 
compared to the coefficients on the margin-related variables, as shown in Table 10 and by discussion of long-term impacts on leverage in Figure 5.

\section{CONCLUSION}

We study a new way to measure regulation and its effects on firm growth, profitability, leverage, and stock returns. Our measure of regulation, NetReg, identifies mentions of the string regulat accompanied by words indicating increasing or decreasing regulation in corporate earnings calls. We believe corporate earnings calls are an ideal setting in which to measure the impact of regulations on firms, and that this setting is equally relevant for all industries regardless of the relevant regulatory bodies. The majority of variation in our regulatory measure is due to idiosyncratic within-firm changes in regulatory exposure, suggesting that our measure captures information that industry- and economy-wide measures cannot reflect.

Higher NetReg has substantial negative effects on future sales growth, asset growth, and leverage from increased regulatory burden expressed in both the Presentation and Q\&A sections of earnings calls. The discussion of regulatory exposure in the Presentation section of earnings calls also has a negative (but lesser) effect on profit margins. Excess stock returns are substantially higher after earnings calls exhibiting higher $\operatorname{NetReg} Q A$.

This suggests that regulatory exposures identified in earnings calls reflect a combination of compliance risk and physical operational costs, with a greater weight on compliance risks that raise returns, reduce growth, and reduce leverage substantially, as opposed to physical operational costs that are deterministic and thus have differing effects from the presence of regulatory risk.

Effects of regulation are smaller for large firms, indicating substantial economies of scale in managing exposure to regulation. The decreased impact of our regulatory measure on future 
corporate outcomes post the Trump election suggests NetReg captured exogenous variation in firm-level regulatory exposure. Finally, the impacts of regulatory exposure exhibit strong variation across different topics of regulation. Exploring the impact of different types of regulatory discussion is an important area for future work.

\section{REFERENCES}

Al-Ubaydli, Omar, and Patrick A. McLaughlin, "RegData: A Numerical Database on Industryspecific Regulations for All United States Industries and Federal Regulations, 1997-2012." Regulation and Governance, 11 (2017), 109-123.

Benmelech, Efraim, and Tobias J. Moskowitz, "The Political Economy of Financial Regulation: Evidence from US State Usury Laws in the 19th Century," J. Finance 65 (2010), 1029-1073.

Bernard, Victor L., and Jacob K. Thomas, "Post-Earnings-Announcement Drift: Delayed Price Response or Risk Premium," Journal of Accounting Research, 27 (1989), 1-36.

Blei, D., A. Ng, and M. Jordan, "Latent Dirichlet allocation," Journal of Machine Learning Research, 3 (2003), 993-1022.

Calomiris, Charles W., "Restoring the Rule of Law in Financial Regulation," Cato Journal, 38 (2018), 701-719.

Calomiris, Charles W., and Stephen H. Haber, Fragile by Design: The Political Origins of Banking Crises and Scarce Credit. (Princeton: Princeton University Press, 2014).

Calomiris, Charles W., and Harry Mamaysky, "How News and Its Context Drive Risk and Returns Around the World," Journal of Financial Economics, 133 (2019), 299-336.

Chan, L., J. Karceski, and J. Lakonishok, "The level and persistence of growth rates," Journal of Finance, 58 (2003), 643-684.

Das, S. and M, Chen, "Yahoo! for Amazon: Sentiment extraction from small talk on the web," Management Science, 53 (2007), 1375-1388.

Davis, Steven J, "Regulatory Complexity and Policy Uncertainty: Headwinds of Our Own Making," Working paper, 2017.

DeMuth, Christopher, "Can the Administrative State Be Tamed," Working Paper, Hoover Institution Initiative on Regulation and the Rule of Law, 2016.

Epstein, Richard A., "The Role of Guidances in Modern Adminstrative Procedures," Working Paper, Hoover Institutions Initiative on Regulation and the Rule of Law, 2016.

Glasserman, Paul, Fulin Li, and Harry Mamaysky, "Time Variation in the News- Returns Relationship," Working paper, 2022. 
Glasserman, P., K. Krstovski, P. Laliberte, and H. Mamaysky, "Choosing news topics to explain stock market returns," 2020.

Gordon, S., and H. Rosenthal, "Political actions by private interests: Mortgage market regulation in the wake of Dodd-Frank," 2014, New York University.

Hassan, T., S. Hollander, L. van Lent, and A. Tahoun, "Firm-level political risk: Measurement and effects," Quarterly Journal of Economics, 134 (2019), 2135-2202.

Jorda, O., "Estimation and inference of impulse responses by local projection," American Economic Review, 95 (2005), 161-182.

Ke, S., J.L. Montiel Olea, and J. Nesbit, "A robust machine learning algorithm for text analysis," Working Paper, (2020).

Ke, Z.T., B. Kelly, and D. Xu, "Predicting returns with text data," Working Paper, (2018).

Kirilenko, A., S. Mankad, G. Michailidis, "Do U.S. financial regulators listen to the public?" June 2014, SSRN.

Kroszner, R. S., \& Strahan, P. E., "What drives deregulation? Economics and politics of the relaxation of bank branching restrictions," Qtrly J. of Economics, 114(4) (1999), 1437-1467.

Krueger, Anne O., "The Political Economy of the Rent-Seeking Society," American Economic Review, 64 (1974), 291-303.

Libgoer, B., "Meetings, comments, and the distributive politics of rulemaking," Qtrly. J. of Political Science, 15 (2020), 449-481.

Loughran, T. and B. McDonald, "When is a liability not a liability? Textual analysis, dictionaries, and 10-Ks," Journal of Finance, 66 (2011), 35-65.

Meursault, V., P. Liang, B. Routledge, and M. Scanlon, "PEAD.txt: Post-EarningsAnnouncement Drift Using Text," working paper (2021).

Olson, Mancur, The Logic of Collective Action: Public Goods and the Theory of Groups. (Cambridge, MA: Harvard University Press, 1965).

Peltzman, S. “Entry in commercial banking," Journal of Law and Economics, 8 (1965), 11-50.

Peltzman, S. "Toward a more general theory of regulation," Journal of Law and Economics, 19 (1976), 211-240.

Price, S, J. Doran, D. Peterson, and B. Bliss, "Earnings conference calls and stock returns: The incremental informativeness of textual tone," J. of Banking \& Finance, 36 (2012), 992-1011.

Simkovic, Michael, and Miao B. Zhang, "Regulation and Technology-Driven Entry: Measurement and Micro-Evidence." Working Paper, 2020.

Steyvers, M. and T. Griffiths, "Probabilistic topic models," in: In T. Landauer, D McNamara, S. Dennis, and W. Kintsch (eds), Lat. Sem. Anal.: Road to Meaning, Laurence Erlbaum, 2007.

Stigler, George J., “The Theory of Economic Regulation,” Bell Journal of Economics and Management Science, 2 (1971), 3-18. 
Stigler, George J., ed., Chicago Studies in Pol. Econ. (University of Chicago Press, 1988).

Tetlock, Paul C., Maytal Saar-Tsechansky, and Sofus Macskassy, "More Than Words:

Quantifying Language to Measure Firms' Fundamentals," J. Finance, 63 (2008), 1437-1467. 


\section{Regulatory measures differ dramatically}
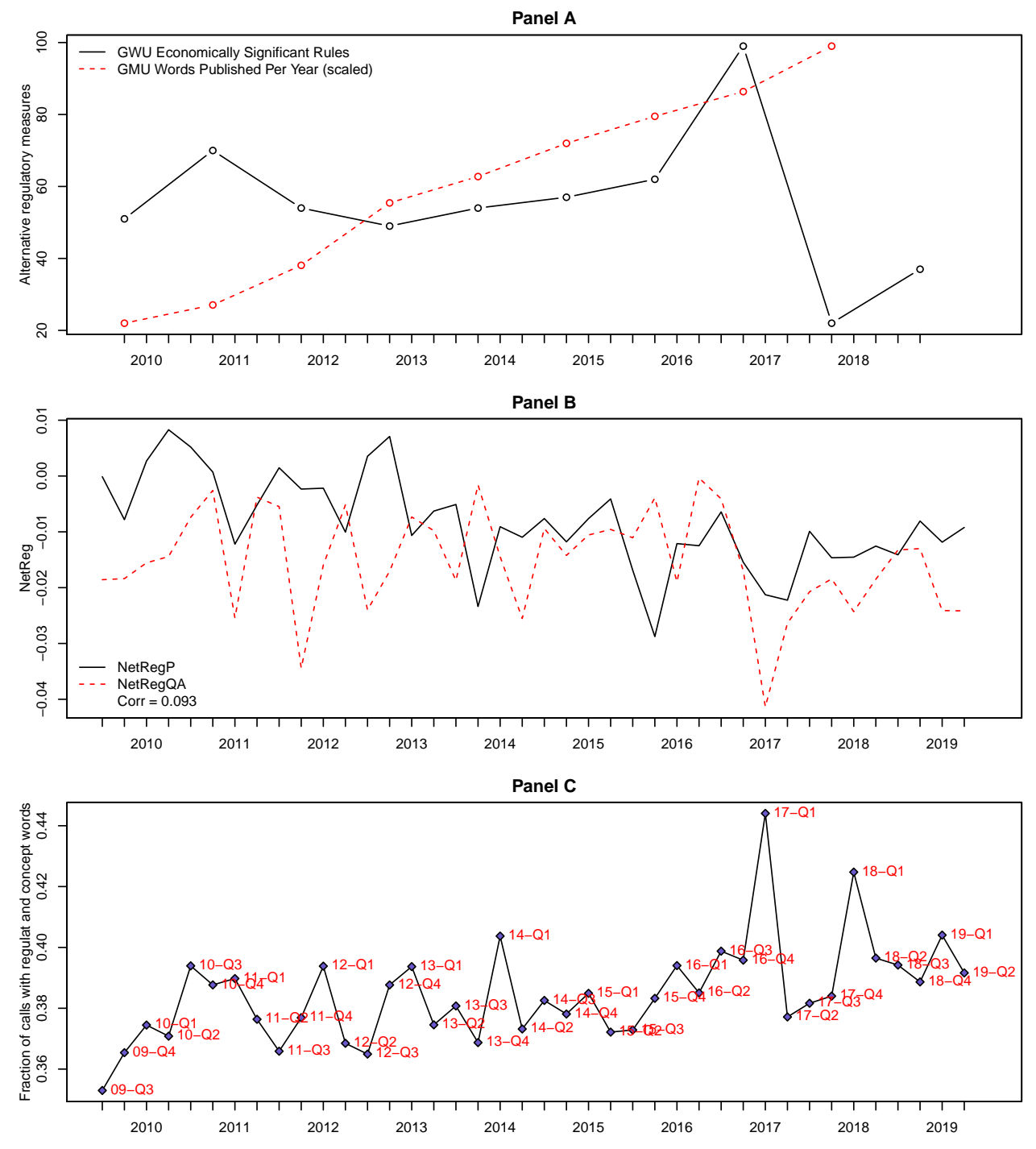

Figure 1: Panel A contrasts the George Mason University's (GMU) approach with the George Washington University's (GWU) approach. The GMU presented by plotting the average, for each year, of the word counts of regulations published across 3-digit NAICS industries. The annual 3-digit NAICS industry-level regulation data comes from Al-Ubaydli and McLaughlin (2017) and are based on the Code of Federal Regulations. GWU refers to the number of economically significant regulatory rules tracked by George Washington University following Executive Order 12866, identifies important regulations with an annual effect on the economy of $\$ 100$ million or more. Panel B plots our measure of regulation NetReg separately for Presentation and Q\&A sections of the quarterly earnings call. Panel $\mathrm{C}$ presents the percentage of all earnings call in the S\&P Global data set that contain at least one sentence in either the presentation or Q\&A portion of the call that satisfies our regulatory filter. 


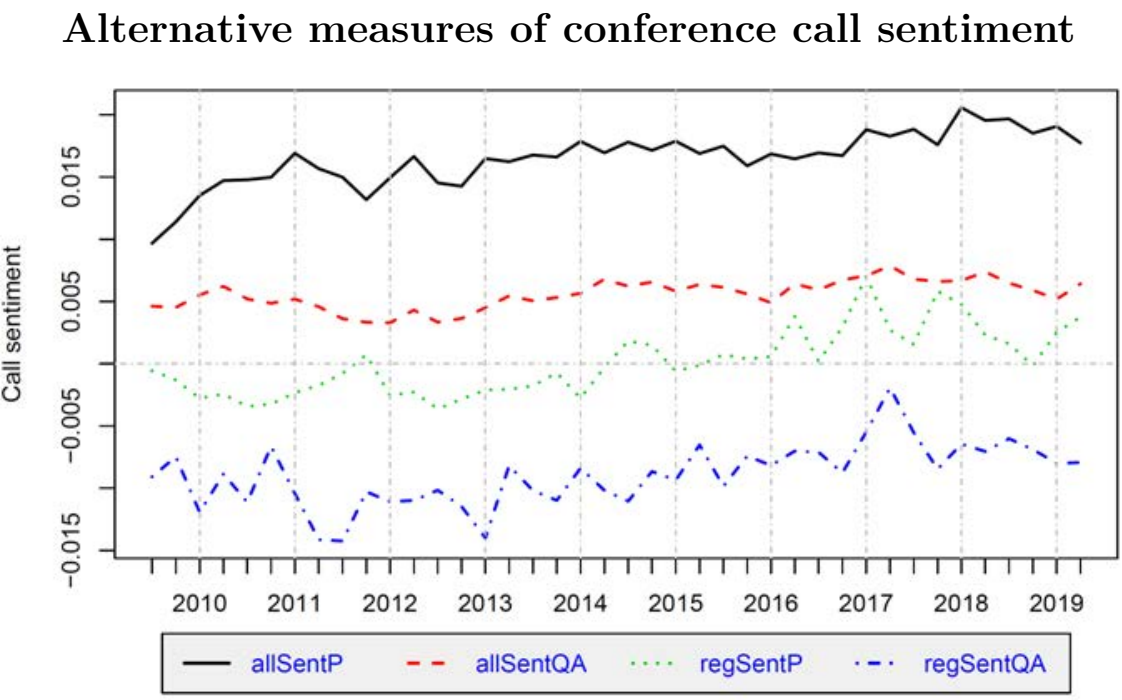

Figure 2: Sentiment series using Loughran-McDonald (LM) dictionary in sentences matching our regulatory filter in the presentation $\left(\operatorname{RegSent} P_{t}\right)$ and Q\&A $\left(\operatorname{Reg} \operatorname{Sent} Q A_{t}\right)$ portions of earnings calls. Also shown are LM sentiment of the presentation (AllSent $\left.P_{t}\right)$ and Q\&A $\left(\right.$ AllSent $\left.Q A_{t}\right)$ portions of the earnings call. The underscore $t$ indicates each series is an equally-weighted average of individual call measures within each quarter. Data are quarterly.

\section{Comparison of trends in NetReg and RegSent}
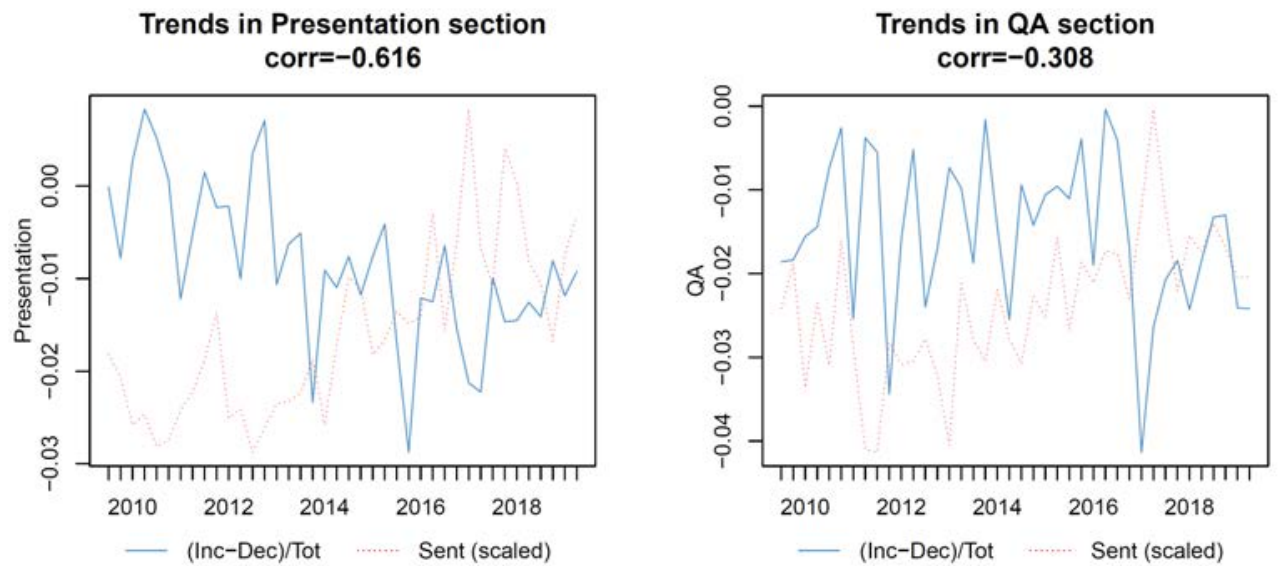

Figure 3: For the presentation portion of earnings call, the left panel shows the net regulatory trends measure $\operatorname{Net} \operatorname{Reg} P_{t}$ (in blue) against a scaled version of the Loughran-McDonald sentiment in sentences matching our regulatory filter RegSent $P_{t}$ (dotted, red line). The right panel shows $N e t \operatorname{Reg} Q A_{t}$ and $\operatorname{Reg} \operatorname{Sent} Q A_{t}$ for the Q\&A portion of the earnings calls. The correlation between the regulatory trends series and the sentence-level sentiment series is shown at the top of each panel. The underscore $t$ indicates each series is an equally-weighted average of individual call measures within each quarter. Data are quarterly. 


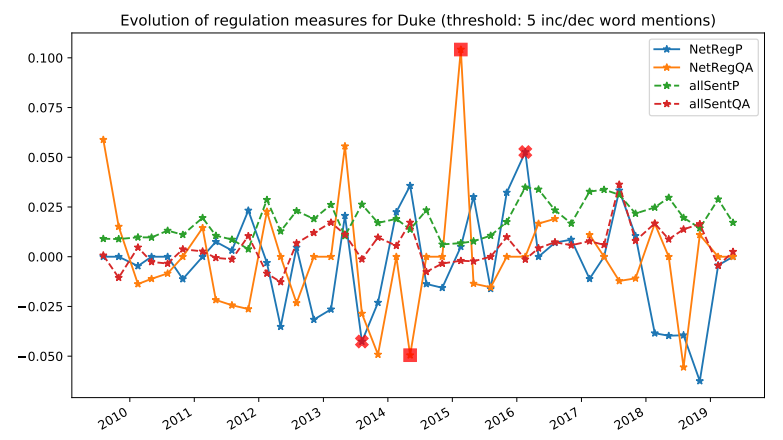

Figure 4: The figure show the evolution of NetReg and AllSent for Duke Energy. The maximum and minimum NetReg points are shown for both the presentation (red X) and Q\&A (red square) sections. The maximum (minimum) is found among all sections of calls that have both positive (negative) NetReg and that mention increasing (decreasing) regulatory modifier words (from Table 3) five or more times. If no such sections exist for a given firm in a given quarter, no NetReg point will be shown; it is possible that a maximum or minimum will not exist because there were no qualifying calls.

\section{Impulse response of sales growth and leverage to a NetReg shock}
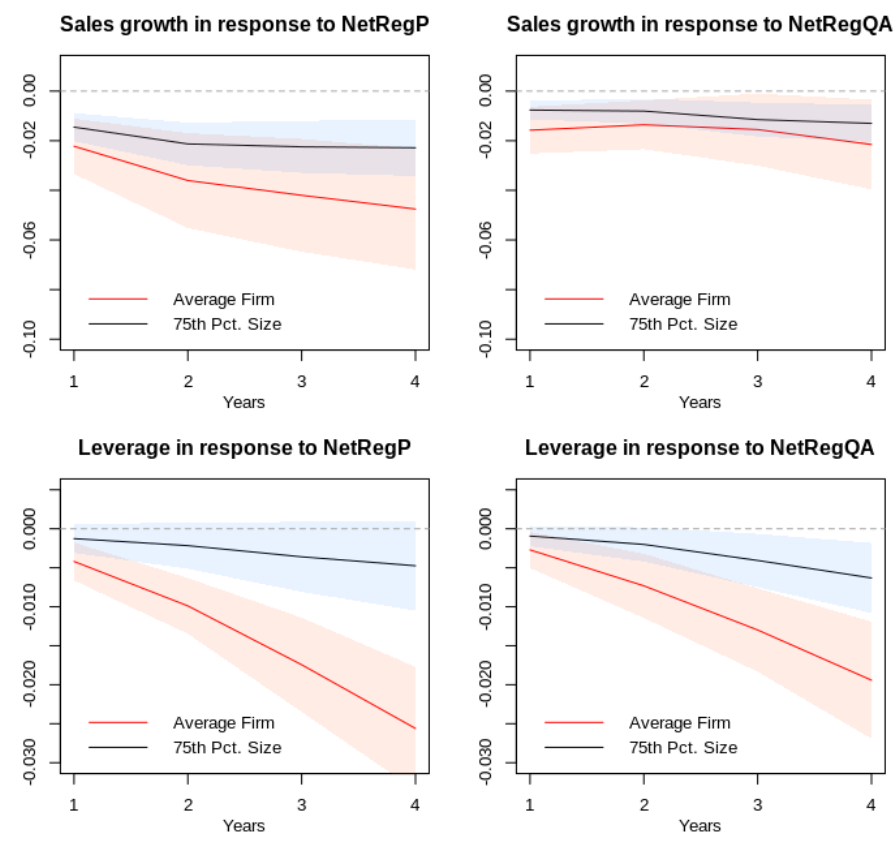

Figure 5: The response of sales growth and leverage to a one-standard deviation shock to NetRegP (presentation) and NetRegQA (Q\&A). We use the local projection method of Jorda (2005) to calculate the cumulative impulse response, as the sum of all prior prior and current single period responses to a one standard deviation shock of the respective NetReg measure. Shown are the cumulative response for an average-sized firm, as well as for a firm in the $75^{\text {th }}$ percentile. The impulse response assumes that the NetReg shock is orthogonal to all other influences. Standard errors assume independence of successive shocks. The bands in the figure show $95 \%$ confidence intervals. 
Table 1: This table outlines the hypotheses motivating our empirical analysis.

\section{Channels of Regulatory Impact}

\begin{tabular}{ll}
\hline Hypothesis & Explanation \\
\hline $\begin{array}{l}\text { H1: If regulatory discussions imply increased regulatory } \\
\text { risk, future expected stock returns should be higher, future } \\
\text { leverage should be lower, and firm growth should be abated. }\end{array}$ & $\begin{array}{l}\text { Increased returns compensate for higher risk. } \\
\text { If the firm was already at an optimal level of leverage } \\
\text { (e.g., based on a tradeoff between expected costs of } \\
\text { distress and tax gains from debt service), } \\
\text { then higher risk should cause reduced leverage. }\end{array}$ \\
& $\begin{array}{l}\text { Higher risk makes incremental growth more costly, } \\
\text { thereby producing a reduction in growth. }\end{array}$ \\
& $\begin{array}{l}\text { Higher physical costs reduce the ratio of profits to sales. } \\
\text { H2: If regulatory discussions imply increased physical } \\
\text { compliance costs, future profit margins and growth both } \\
\text { should be reduced. }\end{array}$ \\
\hline
\end{tabular}

Table 2: For Simkovic and Zhang (2020) (SZ), we calculate the correlation between their 4-digit NAICS industry-year measure and our measure, which we average by industry for each year for comparison purposes. For Hassan et al. (2020), we calculate the correlation between their firm-quarter measure and ours, which is at the same frequency.

\section{Low Correlations with Prior Measures}

\begin{tabular}{lcc}
\hline Paper & Our Measure & Correlation \\
\hline Simkovic and Zhang (2020) measure & NetRegP & 0.017 \\
of regulatory expenditure & NetRegQA & -0.044 \\
\hline Hassan et al. (2019) PRisk & NetRegP & 0.016 \\
& NetRegQA & 0.003 \\
\hline Hassan et al. (2019) PSentiment & RegSentP & 0.003 \\
& RegSentQA & 0.001 \\
\hline
\end{tabular}

Table 3: Shown are stemmed modifying (increasing or decreasing) words. The number of times each stemmed word occurs in the presentation and Q\&A portion of the calls is shown next to each word. Words are arranged in decreasing order of occurrence.

\section{Regulatory directionality word lists}

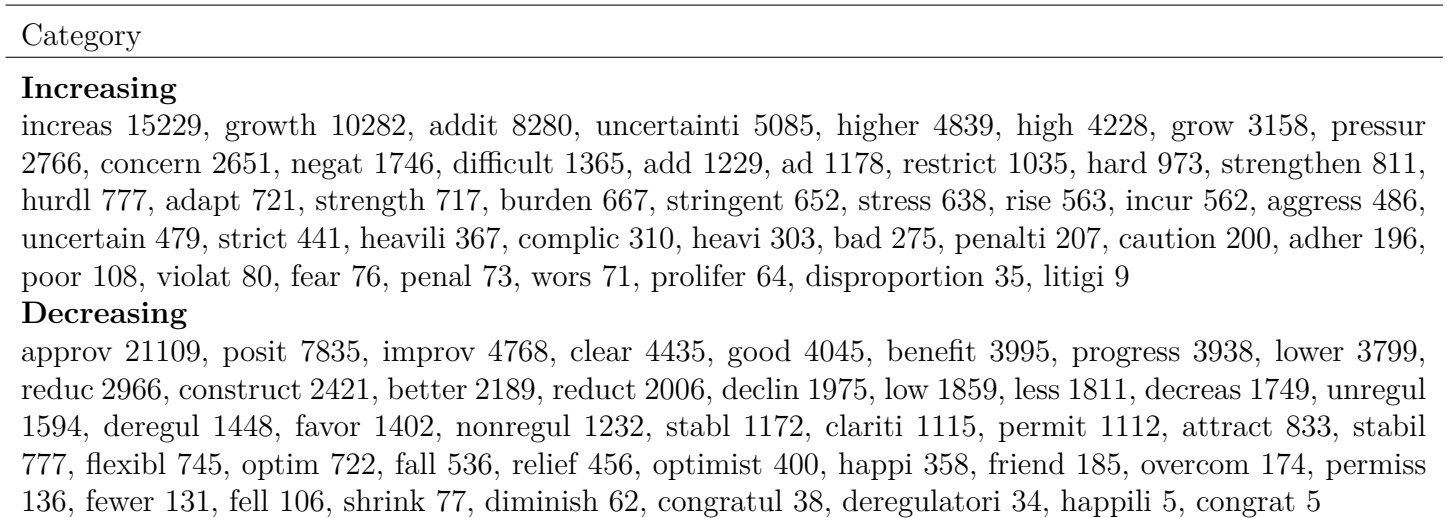


Table 4: Sample sentences that satisfy our regulatory filter from the presentation and Q\&A portions of earnings calls. Each sentence is shown along with its Increasing, Decreasing and Concept words.

\section{Sample sentences}

\begin{tabular}{|c|c|}
\hline & \\
\hline 1 & Iarket's been deregulated. [dec: deregul 1] [inc: \\
\hline 2 & $\begin{array}{l}\text { nd we have less regulatory measures there and also more attractive margins, which is good. } \\
\text { lec: good 1, less 1, attract 1] [inc: ] [concept: measur 1, regulatori 1] }\end{array}$ \\
\hline 3 & $\begin{array}{l}\text { The regulatory approval process is progressing very well. [dec: approv 1, progress 1] [inc: ] } \\
\text { [concept: regulatori } 1 \text {, approv } 1 \text {, progress } 1 \text { ] }\end{array}$ \\
\hline 4 & $\begin{array}{l}\text { We continue to work on regulatory approvals and permitting. [dec: approv 1, permit 1] [inc: } \\
\text { ] [concept: regulatori 1, approv 1] }\end{array}$ \\
\hline 5 & $\begin{array}{l}\text { of petrol and diesel, this is very attractive. [dec: attract } 1 \text {, deregul } \\
1 \text { ] }\end{array}$ \\
\hline 6 & $\begin{array}{l}\text { There are regulatory pressures as you grow and as an industry matures, that's absolutely } \\
\text { normal and we have to adapt to it. [dec: ] [inc: pressur 1, adapt 1, grow 1] [concept: } \\
\text { regulatori 1, pressur 1] }\end{array}$ \\
\hline 7 & $\begin{array}{l}\text { Competition, pricing and regulatory pressure have increased and are increasingly having an } \\
\text { impact on our revenue. [dec: ] [inc: pressur 1, increas 2] [concept: impact 1, regulatori 1, } \\
\text { pressur 1] }\end{array}$ \\
\hline 8 & gulatory burden. [dec: ] [inc: increas 1, burden 1] \\
\hline 9 & $\begin{array}{l}\text { y increased regulatory } \\
\text { nologies. [dec: ] [inc: } \\
\text { ulatori 1, pressur 1, bu }\end{array}$ \\
\hline 10 & $\begin{array}{l}\text { rden grows disproportion- } \\
\text { gulatori } 1 \text {, burden } 1]\end{array}$ \\
\hline 11 & $\begin{array}{l}\text { approvals for construction. [dec: approv 1, construct 1] [inc: ] } \\
\text { 1] }\end{array}$ \\
\hline 12 & $\begin{array}{l}\text { ee regulatory progress. [dec: progress 1, congrat 1] [inc: ] [concept: } \\
\text { 1] }\end{array}$ \\
\hline 13 & $\begin{array}{l}\text { ry friendly, deregulated markets. [dec: deregul 1, friend 1] [inc: ] } \\
\text { egul 1] }\end{array}$ \\
\hline 14 & $\begin{array}{l}\text { A_And again, it's just regulatory approvals. [dec: approv 1] [inc: ] [concept: regulatori } \\
\text { 1, approv 1] }\end{array}$ \\
\hline 5 & $\begin{array}{l}\text { A_ And only about } 1 / 3 \text { of those were for regulatory approvals. [dec: approv 1] [inc: }] \\
\text { [concept: regulatori } 1, \text { approv } 1]\end{array}$ \\
\hline 16 & $\begin{array}{l}\text { A_ It's highly regulated, so the barriers to entry are high. [dec: ] [inc: high 2] [concept: } \\
\text { barrier 1] }\end{array}$ \\
\hline 17 & $\begin{array}{l}\text { A_ And what are the regulatory hurdles? [dec: ] [inc: hurdl 1] [concept: regulatori 1, } \\
\text { hurdl 1] }\end{array}$ \\
\hline 18 & $\begin{array}{l}\text { Q_ Is this because of regulatory pressure? [dec: ] [inc: pressur 1] [concept: regulatori 1, } \\
\text { pressur 1] }\end{array}$ \\
\hline 19 & _A_ Now we're being faced with some of the additional regulatory pressures. [dec: ] [inc: \\
\hline 20 & Q_ Is it regulatory hurdles? [dec: ] [inc: hurdl 1] [concept: regulatori 1, hurdl 1] \\
\hline
\end{tabular}


Table 5: This table describes the data series involving firm fundamental characteristics, market returns, and the S\&P Global earnings call data.

\begin{tabular}{|c|c|}
\hline Variable Name & Description \\
\hline Sales growth & $\begin{array}{l}\text { Percentage growth in sales from quarter } t-4 \text { to quarter } t \text {, where } t \text { is the quarter of the earnings call; } \\
\text { expressed in \% points. }\end{array}$ \\
\hline Asset growth & $\begin{array}{l}\text { Percentage growth in total assets from quarter } t-4 \text { to quarter } t \text {, where } t \text { is the quarter of the earnings } \\
\text { call; expressed in } \% \text { points. }\end{array}$ \\
\hline Operating margin & $\begin{array}{l}\text { Operating income after depreciation divided by sales; all numbers are from the quarter associated with the } \\
\text { earnings call; expressed in \% points. }\end{array}$ \\
\hline Operating margin $\Delta$ & $\begin{array}{l}\text { Change in operating margin from quarter } t-4 \text { to quarter } t \text {, where } t \text { is the quarter of the earnings call; } \\
\text { expressed in } \% \text { points.). }\end{array}$ \\
\hline Gross margin & $\begin{array}{l}\text { Revenues minus cost of goods sold divided by sales; all numbers are from the quarter associated with the } \\
\text { earnings call; expressed in \% points. }\end{array}$ \\
\hline Gross margin $\Delta$ & $\begin{array}{l}\text { Change in gross margin from quarter } t-4 \text { to quarter } t \text {, where } t \text { is the quarter of the earnings call; expressed } \\
\text { in } \% \text { points.). }\end{array}$ \\
\hline Leverage & $\begin{array}{l}\text { Sum of current liabilities and long-term debt divided by total assets; all numbers are from quarter associated } \\
\text { with the earnings call; expressed in } \% \text { points. }\end{array}$ \\
\hline Cost of goods sold & $\begin{array}{l}\text { Cost of goods sold divided by sales; all numbers are from the quarter associated with the earnings call; } \\
\text { expressed in } \% \text { points. }\end{array}$ \\
\hline SG\&A & $\begin{array}{l}\text { SG\&A divided by sales; all numbers are from the quarter associated with the earnings call; expressed in } \\
\% \text { points. }\end{array}$ \\
\hline Excess Ret & $\begin{array}{l}\text { Stock return in excess of the risk-free rate; expressed in \% points. Note: Returns are measured from the } \\
\text { close of day } \mathrm{t} \text { (i.e. the earnings reporting date) for calls occurring prior to } 4 \mathrm{PM} \text { New York time, and from } \\
\text { the close of day } \mathrm{t}+1 \text { (the next business day) for calls occurring after } 4 \mathrm{PM} \text { New York time. }\end{array}$ \\
\hline FF6 Ret & $\begin{array}{l}\text { Excess stock return with respect to the Fama-French (2015) 5-factor model augmented with the momentum } \\
\text { factor; expressed in } \% \text { points. Note: Returns are measured from the close of day t (i.e. the earnings } \\
\text { reporting date) for calls occurring prior to } 4 \mathrm{PM} \text { New York time, and from the close of day t }+1 \text { (the next } \\
\text { business day) for calls occurring after } 4 \mathrm{PM} \text { New York time. }\end{array}$ \\
\hline FF6 Alpha & The alpha estimated from the FF6 model over the trading-day window $[-252,-31] ;$ expressed in $\%$ points. \\
\hline Size & Log sales from the quarter associated with the earnings call \\
\hline $\log (\mathrm{ME})$ & $\begin{array}{l}\text { ME is the closing price times shares outstanding, measured as of the end date of the quarter associated } \\
\text { with the earnings call }\end{array}$ \\
\hline $\log (\mathrm{BM})$ & $\begin{array}{l}\text { BM is book value of common equity divided by market equity, both measured as of the end date of the } \\
\text { quarter associated with the earnings call }\end{array}$ \\
\hline SUE & $\begin{array}{l}\text { Standardized unexpected earnings (SUE) follow the construction in Bernard and Thomas (1989) and Tet- } \\
\text { lock, Saar-Tsechansky, Macskassy (2008). SUE is equal to unexpected earnings (UE) minus mean of UE } \\
\text { across the previous } 20 \text { quarters divided the std. dev. of UE across the previous } 20 \text { quarters. UE is defined } \\
\text { as earnings (i.e. income before extraordinary items) in quarter } t \text {, the quarter of the earnings call, minus } \\
\text { earnings in quarter } t-4 \text {. We set the mean of UE to zero if firms have fewer than } 16 \text { quarters of earnings } \\
\text { data. For the std. dev., firms must have at least } 5 \text { quarters of earnings data; otherwise we treat the std. } \\
\text { dev. as missing. }\end{array}$ \\
\hline $\log ($ share turnover $)$ & $\begin{array}{l}\text { Share turnover is defined as shares traded divided by shares outstanding, on the day of the earnings call if } \\
\text { the call is released prior to } 4 \mathrm{PM} \text {, and otherwise on the next trading day. }\end{array}$ \\
\hline$[\mathrm{Inc} / \mathrm{Dec} / \mathrm{Tot}][\mathrm{P} / \mathrm{QA}]$ & Average number of [increasing/decreasing/total] words in regulatory sentences of the Pres or Q\&A section \\
\hline NetReg[P/QA] & $\begin{array}{l}\text { Net difference of increasing words and decreasing words in regulatory sentences scaled by total words within } \\
\text { that window for the Pres or Q\&A section }\end{array}$ \\
\hline RegSent $[\mathrm{P} / \mathrm{QA}]$ & $\begin{array}{l}\text { Net difference of positive tone words and negative words, based on Loughran and McDonald (2011), within } \\
\text { regulatory sentences scaled by total words within that window for the Pres or Q\&A section }\end{array}$ \\
\hline AllSent [P/QA] & $\begin{array}{l}\text { Net difference of positive tone words and negative words, based on Loughran and McDonald (2011), scaled } \\
\text { by total words for the entire Pres or Q\&A section }\end{array}$ \\
\hline Ind. NetReg[P/QA] & $\begin{array}{l}\text { 2-digit SIC industry average of NetReg[P/QA] over the }[\mathrm{t}-90 . \mathrm{t}] \text { window, where } \mathrm{t} \text { is the date for which the } \\
\text { reporting quarter ends.) }\end{array}$ \\
\hline $\begin{array}{l}\text { Ind. } \\
\text { RegSent }[\mathrm{P} / \mathrm{QA}]\end{array}$ & $\begin{array}{l}\text { 2-digit SIC yearly industry average of RegSent[P/QA] over the }[\mathrm{t}-90 . \mathrm{t}] \text { window, where } \mathrm{t} \text { is the date for } \\
\text { which the reporting quarter ends. }\end{array}$ \\
\hline Ind. AllSent[P/QA] & $\begin{array}{l}\text { 2-digit SIC yearly industry average of AllSent[P/QA] over the }[\mathrm{t}-90 . \mathrm{t}] \text { window, where } \mathrm{t} \text { is the date for which } \\
\text { the reporting quarter ends. }\end{array}$ \\
\hline $\begin{array}{l}\text { Ind. Adj. Ne- } \\
\text { tReg[P/QA] }\end{array}$ & Firm-level NetReg[P/QA] minus Ind. NetReg[P/QA] \\
\hline $\begin{array}{l}\text { Ind. Adj. } \\
\text { RegSent }[\mathrm{P} / \mathrm{QA}]\end{array}$ & Firm-level RegSent[P/QA] minus Ind. RegSent[P/QA] \\
\hline $\begin{array}{l}\text { Ind. Adj. } \\
\text { AllSent[P/QA] }\end{array}$ & Firm-level AllSent[P/QA] minus Ind. AllSent[P/QA] \\
\hline [topic] (Pres) & The average topic distribution of the presentation section of calls. The topics are shown in Figure A1. \\
\hline [topic] (QA) & The average topic distribution of the Q\&A section of calls. The topics are shown in Figure A2. \\
\hline NoRegulat Dummy & $\begin{array}{l}\text { No Regulat Dummy (e.g. for quarter t-4) equals to } 1 \text { if the conference call (e.g. from } 4 \text { quarters ago) had } \\
\text { no mention of "regulat" but if some other earning call for this firm has mentioned "regulat", and equals to } \\
0 \text { otherwise }\end{array}$ \\
\hline $\begin{array}{l}\text { NeverRegulat } \\
\text { Dummy }\end{array}$ & Set to one for firms that have never mentioned "regulat" in any of their conference calls \\
\hline
\end{tabular}


Table 6: Summary statistics for firm-level operating characteristics, returns, and text measures.

\section{Summary statistics}

\begin{tabular}{|c|c|c|c|c|c|c|c|}
\hline Statistic & $\mathrm{N}$ & Mean & St. Dev. & Min & $\operatorname{Pctl}(25)$ & $\operatorname{Pctl}(75)$ & Max \\
\hline Sales Growth & 71,070 & 10.907 & 29.577 & -47.412 & -2.550 & 17.753 & 143.451 \\
\hline Asset Growth & 71,224 & 11.822 & 30.794 & -32.407 & -2.432 & 15.017 & 154.232 \\
\hline Operating Margin & 71,135 & 6.335 & 20.720 & -90.264 & 2.390 & 15.851 & 42.608 \\
\hline Operating Margin $\Delta$ & 70,843 & 1.219 & 13.496 & -37.135 & -2.153 & 2.769 & 67.363 \\
\hline Size (Log Sales) & 71,779 & 5.626 & 1.772 & 1.610 & 4.403 & 6.789 & 11.822 \\
\hline Leverage & 68,623 & 25.495 & 21.328 & 0.000 & 6.438 & 38.335 & 84.294 \\
\hline Gross Margin & 71,156 & 40.894 & 22.666 & -12.621 & 24.238 & 57.030 & 88.437 \\
\hline Gross Margin $\Delta$ & 70,929 & 0.771 & 7.808 & -21.045 & -1.580 & 2.035 & 40.135 \\
\hline Excess Ret (22-day) & 67,581 & 1.524 & 12.931 & -80.591 & -4.889 & 6.990 & 395.474 \\
\hline FF6 Ret (22-day) & 65,391 & 0.216 & 11.637 & -75.771 & -5.250 & 4.810 & 438.124 \\
\hline Excess Ret (Call Day) & 65,287 & 0.158 & 7.800 & -72.312 & -3.295 & 3.574 & 342.934 \\
\hline FF6 Ret (Call Day) & 65,287 & 0.108 & 7.676 & -72.288 & -3.148 & 3.387 & 343.045 \\
\hline Log Share Turnover & 67,802 & -4.167 & 1.093 & -6.997 & -4.829 & -3.431 & -1.931 \\
\hline SUE & 32,931 & -2.412 & 1.836 & -7.161 & -3.467 & -1.164 & 1.622 \\
\hline Log Book-to-Market & 67,912 & -0.959 & 0.809 & -3.138 & -1.425 & -0.397 & 0.748 \\
\hline Log Market Equity & 71,615 & 7.268 & 1.838 & 0.317 & 6.016 & 8.448 & 13.886 \\
\hline IncP & 19,292 & 0.987 & 1.762 & 0.000 & 0.000 & 1.000 & 50.000 \\
\hline DecP & 19,292 & 1.078 & 1.905 & 0.000 & 0.000 & 1.000 & 37.000 \\
\hline TotP & 19,292 & 43.814 & 47.509 & 2.000 & 17.000 & 52.000 & 897.000 \\
\hline NetRegP & 19,292 & -0.004 & 0.052 & -0.333 & -0.020 & 0.013 & 0.429 \\
\hline IncQA & 13,808 & 0.445 & 0.891 & 0.000 & 0.000 & 1.000 & 15.000 \\
\hline DecQA & 13,808 & 0.637 & 1.192 & 0.000 & 0.000 & 1.000 & 42.000 \\
\hline TotQA & 13,808 & 31.542 & 32.588 & 1.000 & 12.000 & 39.000 & 947.000 \\
\hline NetRegQA & 13,808 & -0.007 & 0.054 & -0.667 & -0.018 & 0.000 & 0.500 \\
\hline RegSentP & 18,563 & 0.001 & 0.063 & -0.500 & -0.028 & 0.034 & 0.375 \\
\hline RegSentQA & 12,672 & -0.006 & 0.060 & -0.500 & -0.027 & 0.000 & 0.500 \\
\hline AllSentP & 25,423 & 0.018 & 0.013 & -0.048 & 0.009 & 0.027 & 0.075 \\
\hline AllSentQA & 25,291 & 0.010 & 0.012 & -0.091 & 0.003 & 0.017 & 0.143 \\
\hline Ind. NetRegP & 19,292 & -0.004 & 0.018 & -0.200 & -0.012 & 0.006 & 0.200 \\
\hline Ind. RegSentP & 18,563 & 0.001 & 0.023 & -0.261 & -0.008 & 0.014 & 0.222 \\
\hline Ind. AllSentP & 25,423 & 0.018 & 0.004 & -0.027 & 0.016 & 0.021 & 0.057 \\
\hline Ind. Adj. NetRegP & 19,292 & -0.0001 & 0.048 & -0.334 & -0.018 & 0.020 & 0.419 \\
\hline Ind. Adj. RegSentP & 18,563 & -0.0001 & 0.059 & -0.358 & -0.025 & 0.030 & 0.354 \\
\hline Ind. Adj. AllSentP & 25,423 & -0.00003 & 0.013 & -0.066 & -0.008 & 0.008 & 0.054 \\
\hline Ind. NetRegQA & 13,808 & -0.007 & 0.020 & -0.200 & -0.015 & 0.0001 & 0.231 \\
\hline Ind. RegSentQA & 12,672 & -0.006 & 0.024 & -0.267 & -0.014 & 0.005 & 0.222 \\
\hline Ind. AllSentQA & 25,291 & 0.010 & 0.004 & -0.014 & 0.008 & 0.014 & 0.049 \\
\hline Ind. Adj. NetRegQA & 13,808 & 0.0002 & 0.049 & -0.635 & -0.015 & 0.018 & 0.470 \\
\hline Ind. Adj. RegSentQA & 12,672 & -0.0002 & 0.055 & -0.405 & -0.019 & 0.022 & 0.449 \\
\hline Ind. Adj. AllSentQA & 25,291 & -0.0005 & 0.011 & -0.099 & -0.007 & 0.006 & 0.131 \\
\hline
\end{tabular}


Table 7: This table displays the (incremental) adjusted $R^{2}$ from a projection of our textbased measures on different fixed effects: the $R^{2}$ from a regression with only a time FE (quarter of call); the incremental incremental contribution to $R^{2}$ of adding an industry FE (2-digit SIC) to the time FE regression; and the incremental contribution to $R^{2}$ of adding a firm FE (gvkey) to the time and industry FE regression.

Variance Decomposition of Text-based Measures

\begin{tabular}{lcccccc}
\hline \hline & NetRegP & NetRegQA & RegSentP & RegSentQA & AllSentP & AllSentQA \\
\hline Time FE & 0.0005 & 0.0004 & 0.0007 & 0.0005 & 0.0064 & 0.0093 \\
Industry FE & 0.0148 & 0.0115 & 0.0141 & 0.0044 & 0.0506 & 0.0203 \\
Firm FE & 0.0954 & 0.0345 & 0.1418 & 0.0237 & 0.2721 & 0.2037 \\
\hline
\end{tabular}


Table 8: This table shows a summary of the topic groups for the Presentation and Q\&A sections of the calls. The Frequency column shows the average document topic allocation to the topic group across all earnings calls. The Words column shows the union of the top 10 words by probabiliity in each of the topic-word distributions in each topic group.

\section{Topic group summaries}

\section{Panel A: Presentation topics}

\begin{tabular}{lrl}
\hline Topic & Frequency & Words \\
\hline Euro-Legalese2 & 0.167 & $\begin{array}{l}\text { million, eur, revenu, increas, busi, impact, market, growth, cost, ebitda, state- } \\
\text { ment, risk, forward, result, factor, compani, differ, uncertainti, materi, futur }\end{array}$ \\
FDA & 0.111 & $\begin{array}{l}\text { clinic, approv, develop, product, studi, trial, patient, phase, commerci, fda } \\
\text { Fins }\end{array}$ \\
Legalese & 0.097 & capit, ratio, bank, loan, requir, billion, asset, million, risk, increas \\
M\&A & 0.101 & financi, measur, gaap, call, non, releas, sec, inform, compani, websit \\
& 0.100 & approv, close, transact, process, complet, acquisit, receiv, compani, subject, \\
Margins & 0.079 & announc \\
ProdMktlion, increas, expens, cost, revenu, relat, tax, oper, result, due \\
\end{tabular}

\section{Panel B: Q\&A topics}

\begin{tabular}{|c|c|c|}
\hline Topic & Frequency & Words \\
\hline CorpFin-Util-Margins & 0.269 & $\begin{array}{l}\text { bank, capit, loan, market, littl, good, environ, busi, credit, balanc, rate, } \\
\text { project, util, gas, invest, state, cost, case, custom, million, impact, revenu, } \\
\text { growth, increas, expens, tax }\end{array}$ \\
\hline FDA & 0.102 & data, studi, approv, patient, fda, trial, discuss, product, clinic, phase \\
\hline Fins & 0.087 & capit, bank, risk, ratio, requir, asset, point, level, dividend, impact \\
\hline $\mathrm{M} \& \mathrm{~A}$ & 0.109 & approv, process, close, issu, deal, transact, done, point, hope, review \\
\hline Neg & 0.082 & $\begin{array}{l}\text { regul_NEG, regulatori_NEG, market_NEG, busi_NEG, ca, impact_NEG, } \\
\text { anyth_NEG, issu_NEG, point_NEG, yet_NEG }\end{array}$ \\
\hline ProdMkt-Client-EuroComp & 0.352 & $\begin{array}{l}\text { busi, market, custom, industri, environ, servic, opportun, product, good, } \\
\text { client, price, impact, cours, eur, govern, cost, invest, increas, competit, china, } \\
\text { growth, countri, europ }\end{array}$ \\
\hline
\end{tabular}


Table 9: This table shows the results of regressing four-quarter-ahead sales growth on our net regulatory trends, as well as other control variables. Control variables include company size (log sales), a dummy variable to indicate whether the respective section of a given call had a regulatory mention, a decomposition of net regulatory trends into a company-specific and industry-specific (2-digit SIC code) component, as well as lags and interactions of the above variables. Standard errors, clustered by 2-digit SIC and quarter, are reported in parentheses. Significance is indicated via: ${ }^{*} \mathrm{p}<0.1 ;{ }^{*} \mathrm{p}<0.05 ;{ }^{* *} \mathrm{p}<0.01$.

\section{Effects of NetReg on sales growth}

\begin{tabular}{|c|c|c|c|c|c|c|c|c|}
\hline & & & & Sales C & $\operatorname{owth}_{t+4}^{i}$ & & & \\
\hline & $(1)$ & $(2)$ & $(3)$ & $(4)$ & $(5)$ & $(6)$ & $(7)$ & $(8)$ \\
\hline NetRegP $P_{t}^{i}$ & $\begin{array}{c}-31.263^{* * *} \\
(6.374)\end{array}$ & & $\begin{array}{c}-43.030^{* * *} \\
(11.005)\end{array}$ & & & & $\begin{array}{c}-30.080^{* * *} \\
(7.743)\end{array}$ & \\
\hline $\operatorname{NetRegQA}_{t}^{i}$ & & $\begin{array}{c}-17.073^{* * *} \\
(3.509)\end{array}$ & & $\begin{array}{c}-29.433^{* * *} \\
(8.992)\end{array}$ & & & & $\begin{array}{c}-15.234^{* * *} \\
(5.238)\end{array}$ \\
\hline Ind. Adj. NetRegP $P_{t}^{i}$ & & & & & $\begin{array}{l}-32.046^{* * *} \\
(9.732)\end{array}$ & & & \\
\hline Ind. Adj. NetRegQA ${ }_{t}^{i}$ & & & & & & $\begin{array}{l}-18.376^{* * *} \\
(6.112)\end{array}$ & & \\
\hline $\operatorname{NetRegP}_{t-4}^{i}$ & & & & & & & $\begin{array}{l}-17.223 \\
(12.025)\end{array}$ & \\
\hline NetRegQA $t_{t-4}^{i}$ & & & & & & & & $\begin{array}{c}2.497 \\
(5.816)\end{array}$ \\
\hline $\operatorname{Size}_{t}^{i}$ & $\begin{array}{c}-3.481^{* * *} \\
(0.878)\end{array}$ & $\begin{array}{c}-3.407^{* * *} \\
(0.840)\end{array}$ & $\begin{array}{c}-3.461^{* * *} \\
(0.859)\end{array}$ & $\begin{array}{c}-3.384^{* * *} \\
(0.818)\end{array}$ & $\begin{array}{c}-3.479^{* * *} \\
(0.874)\end{array}$ & $\begin{array}{c}-3.406^{* * *} \\
(0.838)\end{array}$ & $\begin{array}{c}-2.930^{* * *} \\
(0.839)\end{array}$ & $\begin{array}{c}-2.739^{* * *} \\
(0.731)\end{array}$ \\
\hline Ind. NetRegP $P_{t}^{i}$ & & & & & $\begin{array}{c}-64.050^{* * *} \\
(21.946)\end{array}$ & & & \\
\hline Ind. NetRegQA ${ }_{t}^{i}$ & & & & & & $\begin{array}{c}-38.662^{* *} \\
(16.821)\end{array}$ & & \\
\hline Sales Growth ${ }_{t}^{i}$ & $\begin{array}{l}0.070^{* *} \\
(0.031)\end{array}$ & $\begin{array}{l}0.072^{* *} \\
(0.032)\end{array}$ & $\begin{array}{l}0.070^{* *} \\
(0.031)\end{array}$ & $\begin{array}{l}0.072^{* *} \\
(0.032)\end{array}$ & $\begin{array}{l}0.070^{* *} \\
(0.031)\end{array}$ & $\begin{array}{l}0.072^{* *} \\
(0.032)\end{array}$ & $\begin{array}{c}0.080^{* * *} \\
(0.031)\end{array}$ & $\begin{array}{c}0.089^{* * *} \\
(0.031)\end{array}$ \\
\hline No Regulat Dummy ${ }_{t}^{i}$ & $\begin{array}{l}-1.329 \\
(1.068)\end{array}$ & $\begin{array}{c}-2.663^{*} \\
(1.362)\end{array}$ & $\begin{array}{l}-1.371 \\
(1.066)\end{array}$ & $\begin{array}{c}-2.655^{* *} \\
(1.350)\end{array}$ & $\begin{array}{l}-1.283 \\
(1.007)\end{array}$ & $\begin{array}{c}-2.541^{*} \\
(1.302)\end{array}$ & $\begin{array}{c}-1.699^{* * *} \\
(0.650)\end{array}$ & $\begin{array}{l}-2.826^{* * *} \\
(1.042)\end{array}$ \\
\hline No Regulat Dummy ${ }_{t-4}^{i}$ & & & & & & & $\begin{array}{c}0.702 \\
(1.048)\end{array}$ & $\begin{array}{c}0.123 \\
(1.127)\end{array}$ \\
\hline Never Regulat Dummy ${ }_{t}^{i}$ & $\begin{array}{c}-5.314^{* * *} \\
(1.878)\end{array}$ & $\begin{array}{c}-6.602^{* * *} \\
(2.141)\end{array}$ & $\begin{array}{c}-5.334^{* * *} \\
(1.859)\end{array}$ & $\begin{array}{c}-6.570^{* * *} \\
(2.107)\end{array}$ & $\begin{array}{c}-5.286^{* * *} \\
(1.816)\end{array}$ & $\begin{array}{c}-6.487^{* * *} \\
(2.082)\end{array}$ & $\begin{array}{c}-4.597^{* *} \\
(2.140)\end{array}$ & $\begin{array}{c}-6.093^{* *} \\
(2.575)\end{array}$ \\
\hline $\operatorname{NetRegP}{ }_{t}^{i} \operatorname{Size}_{t}^{i}$ & & & $\begin{array}{l}9.024^{*} \\
(4.843)\end{array}$ & & & & & \\
\hline $\operatorname{NetRegQA}_{t}^{i *} \operatorname{Size}_{t}^{i}$ & & & & $\begin{array}{c}9.163 \\
(6.036)\end{array}$ & & & & \\
\hline Ind. Adj. NetRegP $P_{t}^{i *} \operatorname{Size}_{t}^{i}$ & & & & & $\begin{array}{c}4.344 \\
(3.812)\end{array}$ & & & \\
\hline Ind. Adj. NetRegQA ${ }_{t}^{i *} \operatorname{Size}_{t}^{i}$ & & & & & & $\begin{array}{c}3.747 \\
(3.412) \\
\end{array}$ & & \\
\hline 2-digit SIC Ind. FE? & Yes & Yes & Yes & Yes & Yes & Yes & Yes & Yes \\
\hline Observations & 55,162 & 50,757 & 55,162 & 50,757 & 55,162 & 50,757 & 39,287 & 35,280 \\
\hline $\mathrm{R}^{2}$ & 0.078 & 0.075 & 0.078 & 0.076 & 0.078 & 0.075 & 0.071 & 0.065 \\
\hline Adjusted $\mathrm{R}^{2}$ & 0.077 & 0.074 & 0.077 & 0.074 & 0.077 & 0.074 & 0.070 & 0.064 \\
\hline
\end{tabular}


Table 10: This table summarizes the main results for our overall sample (Panel A), small firm (i.e. 10th size percentile, Panel B), large firm (i.e. 90th size percentile, Panel C) in terms of annual percentage (one-year ahead) effects for sales growth, asset growth, leverage, operating margin, gross margin, change in operating margins, and change in gross margins. Standard errors are clustered by 2-digit SIC and quarter. Panel D display the effects on returns (in percentages). These standard errors are clustered by 2-digit SIC and earnings call date. For FF6 returns, the factor loadings used to calculate these risk-adjusted, or abnormal, returns and alphas are estimated over a training window from 252 to 31 trading days prior to the earnings call. In the 22-trading day period following each earnings call, we use $[t, t+22]$ returns for pre-4pm day $t$ calls, and $[t+1, t+23]$ for post-4pm day $t$ calls. Coefficients denote the effect from a one standard deviation increase in the independent variable. Non-missing entries reflect effects that are significant at the $10 \%$ level. Significance is indicated via: ${ }^{*} \mathrm{p}<0.1 ;{ }^{* *} \mathrm{p}<0.05 ;{ }^{* * *} \mathrm{p}<0.01$.

\section{Impacts of NetReg and AllSent on Firm Outcomes}

\begin{tabular}{|c|c|c|c|c|}
\hline Panel A: Overall & NetRegP & NetRegQA & AllSentP & AllSentQA \\
\hline $\begin{array}{l}\text { Sales Growth } \\
\text { Asset Growth } \\
\text { Leverage } \\
\text { Operating Margin } \\
\text { Gross Margin } \\
\text { Operating Margin } \Delta \\
\text { Gross Margin } \Delta\end{array}$ & $\begin{array}{c}-1.616^{* * *} \\
-1.364^{* * *} \\
-0.192^{*} \\
-0.331^{* * *} \\
-0.347^{* *} \\
-0.281^{* * *}\end{array}$ & $\begin{array}{l}-0.882^{* * *} \\
-0.582^{*} \\
-0.123^{*}\end{array}$ & $1.489^{* * *}$ & $1.174^{* * *}$ \\
\hline Panel B: Small Firm & NetRegP & NetRegQA & AllSentP & AllSentQA \\
\hline $\begin{array}{l}\text { Sales Growth } \\
\text { Asset Growth } \\
\text { Leverage } \\
\text { Operating Margin } \\
\text { Gross Margin } \\
\text { Operating Margin } \Delta \\
\text { Gross Margin } \Delta\end{array}$ & $\begin{array}{l}-3.103^{* * *} \\
-1.502^{* *} \\
-0.766^{* * *} \\
-0.618^{* * *} \\
-1.103^{* *} \\
-0.681^{* *} \\
\end{array}$ & $\begin{array}{l}-2.500^{* *} \\
-1.160^{* *} \\
-0.486^{* *}\end{array}$ & $\begin{array}{c}0.950^{* *} \\
2.065^{* * *} \\
0.400^{* * *} \\
-0.834^{*}\end{array}$ & $0.986^{* * *}$ \\
\hline Panel C: Large Firm & NetRegP & NetRegQA & AllSentP & AllSentQA \\
\hline $\begin{array}{l}\text { Sales Growth } \\
\text { Asset Growth } \\
\text { Leverage } \\
\text { Operating Margin } \\
\text { Gross Margin } \\
\text { Operating Margin } \Delta \\
\text { Gross Margin } \Delta\end{array}$ & $\begin{array}{c}-0.821^{* *} \\
-1.289^{* * *}\end{array}$ & $0.295^{*}$ & $1.126^{* * *}$ & $\begin{array}{c}0.990^{*} \\
1.069^{* * *}\end{array}$ \\
\hline Panel D: Returns & NetRegP & NetRegQA & AllSentP & AllSentQA \\
\hline $\begin{array}{l}\text { Excess Ret (22-day) } \\
\text { FF6 Ret (22-day) } \\
\text { Excess Ret (Call Day) } \\
\text { FF6 Ret (Call Day) }\end{array}$ & & $\begin{array}{c}0.221^{* *} \\
0.152^{*}\end{array}$ & $\begin{array}{c}0.186^{* *} \\
0.252^{* * *} \\
0.664^{* * *} \\
0.808^{* * *}\end{array}$ & $\begin{array}{l}0.411^{* * *} \\
0.357^{* * *} \\
0.674^{* * *} \\
0.808^{* * *}\end{array}$ \\
\hline
\end{tabular}


Table 11: This table shows that our main firm performance measures generally do not forecast NetReg for firm $i$ in quarter $t$ while showing that sentiment captures broad perceptions of firm prospects. Coefficients denote the effect from a one standard deviation increase in the independent variable (i.e. lag 1-month returns, sales growth, asset growth, and operating margin growth). Non-missing entries reflect effects that are significant at the $10 \%$ level. Significance is indicated via: ${ }^{*} \mathrm{p}<0.1 ;{ }^{*} \mathrm{p}<0.05 ;{ }^{*} *{ }^{*} \mathrm{p}<0.01$.

Does Firm Performance Forecast Our NLP-based Measures?

\begin{tabular}{|c|c|c|c|c|}
\hline & NetRegP $P_{t}^{i}$ & $\operatorname{NetRegQA}_{t}^{i}$ & AllSentP $_{t}^{i}$ & AllSentQA $_{t}^{i}$ \\
\hline Lag Month FF6 Ret & & & $0.001^{* * *}$ & $0.001^{* * *}$ \\
\hline Sales Growth ${ }_{t-4 \cdot t}^{i}$ & & & $0.002^{* * *}$ & $0.001^{* * *}$ \\
\hline Asset Growth $h_{t-4 ; t}^{i}$ & & & $-0.001 * * *$ & $-0.000^{* * *}$ \\
\hline Operating Margin $\Delta_{t-4 ; t}^{i}$ & & & & \\
\hline Sales Growth ${ }_{t-8 ; t-4}^{i}$ & & & $-0.001 * * *$ & $-0.001 * * *$ \\
\hline Asset Growth ${ }_{t-8 ; t-4}^{i}$ & & & $-0.000 * * *$ & $-0.000 * *$ \\
\hline Operating Margin $\Delta_{t-8 ; t-4}^{i}$ & & & & \\
\hline
\end{tabular}


Table 12: This table shows the results of regressions which include NetReg, a postinauguration dummy for the Trump election, and the interaction term NetReg $\times$ Post-Inuguration as controls for the following dependent variables: sales growth, asset growth, leverage, operating margin, gross margin, operating margin $\Delta$, gross margin $\Delta$. The time period is restricted to dependent variables (which are one-year ahead outcomes) with starting dates from January 1, 2015 to January 31, 2018. Observations with dependent variable starting dates from April 20, 2016 to October 20, 2016 are omitted. This is a sixmonth period centered on the cutoff date of July 20, 2016, which is the date six months prior to the inauguration held on January 20, 2017. The post-inauguration dummy is set to one for dependent variables with starting dates after October 20, 2016. The sample is restricted to firms that exist both before and after the July 20, 2016 cutoff. Control variables include company size (log sales), a dummy variable to indicate whether the respective section of a given call had a regulatory mention, a dummy variable to indicate whether the respective company never had a regulatory mention in any call, and the lagged dependent variable. Coefficients estimates for NetReg and NetReg $\times$ Post-Inauguration denote the effect from a one standard deviation increase in NetReg. Standard errors, clustered by 2-digit SIC and quarter, are in the parentheses. Significance is indicated via: ${ }^{*} \mathrm{p}<0.1 ;{ }^{* *} \mathrm{p}<0.05 ;{ }^{*} * *_{\mathrm{p}}<0.01$.

\section{Effects of NetReg Around Trump Inauguration}

\begin{tabular}{lcc}
\hline \hline Panel A: Presentation & NetRegP & NetRegP $\times$ Post-Inauguration \\
\hline Sales Growth & $-2.574^{* * *}$ & 0.647 \\
Asset Growth & $-2.246^{* * *}$ & 0.725 \\
Leverage & $-0.549^{*}$ & 0.262 \\
Operating Margin & -0.353 & 0.493 \\
Gross Margin & $-0.599^{* * *}$ & $0.275^{* *}$ \\
Operating Margin $\Delta$ & $-0.688^{* * *}$ & $0.109^{* * *}$ \\
Gross Margin $\Delta$ & $-0.594^{* * *}$ & $0.205^{* *}$ \\
\hline Panel A: Q\&A & NetRegQA & NetRegQA $\times$ Post-Inauguration \\
\hline Sales Growth & $-1.218^{* * *}$ & $1.204^{* *}$ \\
Asset Growth & -0.808 & $1.295^{* * *}$ \\
Leverage & -0.018 & -0.020 \\
Operating Margin & -0.061 & 0.463 \\
Gross Margin & $-0.386^{* *}$ & $0.473^{* * *}$ \\
Operating Margin $\Delta$ & $-0.707^{*}$ & $0.604^{* * *}$ \\
Gross Margin $\Delta$ & $-0.392^{*}$ & $0.170^{* * *}$ \\
\hline
\end{tabular}


Table 13: This table shows that the decomposition of the effects of NetReg by topic on sales growth, asset growth, and leverage. Control variables include company size (log sales), a dummy variable to indicate whetherthe respective section of a given call had a regulatory mention. Standard errors, clustered by 2-digit SIC and quarter, are reported in the parentheses. Significance is indicated via: ${ }^{*} \mathrm{p}<0.1 ;{ }^{*} \mathrm{p}<0.05 ;{ }^{*} * \mathrm{p}<0.01$.

Effects of NetReg by topic on firm growth and leverage

\begin{tabular}{|c|c|c|c|c|c|c|}
\hline & \multicolumn{2}{|c|}{ Sales Growth ${ }_{t+4}^{i}$} & \multicolumn{2}{|c|}{ Asset Growth ${ }_{t+4}^{i}$} & \multicolumn{2}{|c|}{ Leverage $_{t+4}^{i}$} \\
\hline & $(1)$ & $(2)$ & (3) & $(4)$ & $(5)$ & $(6)$ \\
\hline $\operatorname{Size}_{t}^{i}$ & $\begin{array}{c}-3.335^{* * *} \\
(0.942)\end{array}$ & $\begin{array}{c}-3.191^{* * *} \\
(0.739)\end{array}$ & $\begin{array}{c}-1.263^{* * *} \\
(0.330)\end{array}$ & $\begin{array}{c}-1.355^{* * *} \\
(0.312)\end{array}$ & $\begin{array}{c}0.305^{* * *} \\
(0.074)\end{array}$ & $\begin{array}{c}0.302^{* * *} \\
(0.090)\end{array}$ \\
\hline Sales Growth $_{t}^{i}$ & $\begin{array}{c}0.076 \\
(0.050)\end{array}$ & $\begin{array}{l}0.078^{*} \\
(0.040)\end{array}$ & & & & \\
\hline Asset Growth ${ }_{t}^{i}$ & & & $\begin{array}{c}0.128^{* * *} \\
(0.030)\end{array}$ & $\begin{array}{c}0.129^{* * *} \\
(0.022)\end{array}$ & & \\
\hline Leverage $_{t}^{i}$ & & & & & $\begin{array}{c}0.901^{* * *} \\
(0.009)\end{array}$ & $\begin{array}{c}0.901^{* * *} \\
(0.009)\end{array}$ \\
\hline No Regulat Dummy ${ }_{t-4}^{i}$ & $\begin{array}{l}-0.896 \\
(1.054)\end{array}$ & $\begin{array}{c}-2.385^{*} \\
(1.236)\end{array}$ & $\begin{array}{l}-0.249 \\
(1.046)\end{array}$ & $\begin{array}{c}-2.321^{* * *} \\
(0.737)\end{array}$ & $\begin{array}{l}-0.039 \\
(0.153)\end{array}$ & $\begin{array}{l}-0.146 \\
(0.217)\end{array}$ \\
\hline Never Regulat Dummy ${ }_{t}^{i}$ & $\begin{array}{l}-4.722^{* * *} \\
(1.791)\end{array}$ & $\begin{array}{l}-6.080^{* * *} \\
(1.920)\end{array}$ & $\begin{array}{l}-2.814^{*} \\
(1.581)\end{array}$ & $\begin{array}{l}-5.070^{* * *} \\
(1.047)\end{array}$ & $\begin{array}{c}-0.605^{* *} \\
(0.237)\end{array}$ & $\begin{array}{c}-0.719^{* *} \\
(0.307)\end{array}$ \\
\hline Legalese (Pres. $)_{t}^{i *} \operatorname{NetReg} P_{t}^{i}$ & $\begin{array}{l}-54.833 \\
(56.356)\end{array}$ & & $\begin{array}{l}-7.259 \\
(49.602)\end{array}$ & & $\begin{array}{l}-22.744 \\
(13.899)\end{array}$ & \\
\hline FDA (Pres. $)_{t}^{i *} \operatorname{NetRegP}_{t}^{i}$ & $\begin{array}{l}-61.797^{* *} \\
(29.541)\end{array}$ & & $\begin{array}{c}23.991 \\
(18.621)\end{array}$ & & $\begin{array}{l}-17.675^{* * *} \\
(3.680)\end{array}$ & \\
\hline Fins (Pres. $)_{t}^{i}{ }^{*} \operatorname{NetReg} \mathrm{P}_{t}^{i}$ & $\begin{array}{l}-15.373 \\
(78.923)\end{array}$ & & $\begin{array}{l}-76.834 \\
(94.818)\end{array}$ & & $\begin{array}{c}15.497 \\
(19.651)\end{array}$ & \\
\hline Margins (Pres. $)_{t}^{i *} \operatorname{NetReg}_{t}^{i}$ & $\begin{array}{l}-18.870 \\
(23.954)\end{array}$ & & $\begin{array}{c}27.227 \\
(22.606)\end{array}$ & & $\begin{array}{c}-7.584^{*} \\
(3.948)\end{array}$ & \\
\hline Util (Pres.) ${ }_{t}^{i}{ }^{*} \operatorname{NetReg} \mathrm{P}_{t}^{i}$ & $\begin{array}{l}-10.318 \\
(15.638)\end{array}$ & & $\begin{array}{l}38.009^{*} \\
(20.482)\end{array}$ & & $\begin{array}{c}10.668^{* *} \\
(5.124)\end{array}$ & \\
\hline $\mathrm{M} \& \mathrm{~A}(\text { Pres. })_{t}^{i *} \operatorname{NetReg} \mathrm{P}_{t}^{i}$ & $\begin{array}{c}-135.768^{* * *} \\
(23.871)\end{array}$ & & $\begin{array}{l}-206.571^{* * *} \\
(28.936)\end{array}$ & & $\begin{array}{l}-16.819^{* * *} \\
(4.527)\end{array}$ & \\
\hline ProdMkt-Client (Pres. $)_{t}^{i}{ }^{*} \operatorname{NetRegP}_{t}^{i}$ & $\begin{array}{l}-2.005 \\
(5.868)\end{array}$ & & $\begin{array}{l}11.870 \\
(7.992)\end{array}$ & & $\begin{array}{l}-3.309 \\
(3.467)\end{array}$ & \\
\hline Euro-Legalese2 (Pres.) ${ }_{t}^{i} * \operatorname{NetReg} \mathrm{P}_{t}^{i}$ & $\begin{array}{l}-48.662^{*} \\
(28.836)\end{array}$ & & $\begin{array}{c}-67.691^{* *} \\
(34.333)\end{array}$ & & $\begin{array}{l}10.491 \\
(7.587)\end{array}$ & \\
\hline $\mathrm{FDA}(\mathrm{QA})_{t}^{i *} \operatorname{NetReg} \mathrm{A}_{t}^{i}$ & & $\begin{array}{c}-91.991^{* *} \\
(36.217)\end{array}$ & & $\begin{array}{c}0.215 \\
(24.931)\end{array}$ & & $\begin{array}{c}8.625 \\
(6.521)\end{array}$ \\
\hline $\mathrm{M} \& \mathrm{~A}(\mathrm{QA})_{t}^{i *} \mathrm{NetRegQA}_{t}^{i}$ & & $\begin{array}{l}-66.126^{* * *} \\
(21.456)\end{array}$ & & $\begin{array}{l}-49.005^{* *} \\
(22.551)\end{array}$ & & $\begin{array}{l}-0.718 \\
(4.903)\end{array}$ \\
\hline Fins $(\mathrm{QA})_{t}^{i *} \operatorname{NetReg} A_{t}^{i}$ & & $\begin{array}{c}2.496 \\
(54.483)\end{array}$ & & $\begin{array}{c}30.947 \\
(61.385)\end{array}$ & & $\begin{array}{c}-28.526^{* *} \\
(12.380)\end{array}$ \\
\hline $\operatorname{Neg}(\mathrm{QA})_{t}^{i *} \operatorname{NetRegQA} A_{t}^{i}$ & & $\begin{array}{l}-12.147 \\
(46.000)\end{array}$ & & $\begin{array}{c}-61.484 \\
(47.521)\end{array}$ & & $\begin{array}{c}-9.833 \\
(10.848)\end{array}$ \\
\hline ProdMkt-Client-Euro $(\mathrm{QA})_{t}^{i * N e t R e g Q A_{t}^{i}}$ & & $\begin{array}{l}-2.683 \\
(7.159)\end{array}$ & & $\begin{array}{l}-7.234 \\
(14.710)\end{array}$ & & $\begin{array}{l}-0.863 \\
(2.418)\end{array}$ \\
\hline CorpFin-Util-Margins $(\mathrm{QA})_{t}^{i} * \operatorname{NetRegQA} t_{t}^{i}$ & & $\begin{array}{c}-1.908 \\
(11.804) \\
\end{array}$ & & $\begin{array}{c}-2.831 \\
(10.366) \\
\end{array}$ & & $\begin{array}{l}-5.793 \\
(3.950) \\
\end{array}$ \\
\hline 2-digit SIC Ind. FE? & Yes & Yes & Yes & Yes & Yes & Yes \\
\hline Observations & 55,018 & 50,609 & 55,188 & 50,751 & 52,962 & 48,725 \\
\hline $\mathrm{R}^{2}$ & 0.075 & 0.071 & 0.051 & 0.052 & 0.849 & 0.851 \\
\hline Adjusted $\mathrm{R}^{2}$ & 0.074 & 0.070 & 0.050 & 0.050 & 0.849 & 0.851 \\
\hline
\end{tabular}

